\title{
Health Insurance Coverage and Health Care Utilization: Evidence from the Affordable Care Act's Dependent Coverage Mandate
}

\author{
Barış K. Yörük
}

CESIFO WORKING PAPER NO. 6277

Category 3: Social Protection

DECEMBER 2016

An electronic version of the paper may be downloaded
• from the SSRN website:
- from the RePEc website:
- from the CESifo website: 


\title{
Health Insurance Coverage and Health Care Utilization: Evidence from the Affordable Care Act's Dependent Coverage Mandate
}

\begin{abstract}
This paper investigates the impact of the Affordable Care Act's (ACA's) dependent coverage mandate on health insurance coverage rates and health care utilization among young adults. Using data from the Medical Panel Expenditure Survey, I exploit the discontinuity in health insurance coverage rates at age 26, the new dependent coverage age cutoff enforced by the ACA. Under alternative regression discontinuity design models, I find that $2.5 \%$ to $5.3 \%$ of young adults lose their health insurance coverage once they turn 26. This effect is mainly driven by those who lose their private health insurance plan coverage and those who lose their health insurance plan coverage, whose main holder resides outside of the household. I also find that the discrete change in health insurance coverage rates at age 26 is associated with significant changes in office-based physician and dental visits, but does not have a significant impact on the utilization of outpatient or emergency department services. Furthermore, the effects of the ACA's dependent coverage mandate on health care spending and out-of-pocket costs are insignificant. These results are robust under alternative model specifications.
\end{abstract}

JEL-Codes: I120, I130, I180.

Keywords: affordable care act, health insurance coverage, health care utilization, dependent coverage.

\author{
Barış K. Yörük \\ Department of Economics \\ University at Albany, SUNY \\ 1400 Washington Ave. \\ USA - Albany, NY 12222 \\ byoruk@albany.edu
}

December 4, 2016

I thank Marcus Dillender and session participants at the 6th biennial conference of American

Society of Health Economists for helpful comments. All errors remain mine. 


\section{Introduction}

In 2012, over one-quarter of 19-25 year olds in the United States were without health insurance (Kirzinger, Cohen, and Gindi, 2013). ${ }^{1}$ Several factors are likely to contribute to low insurance rates among this age group including low entry-level wages, high health insurance premiums, and jobs without any employer sponsored insurance plans. Furthermore, compared to other age groups, young adults are relatively healthy and less likely to use medical services, which may make the cost of insurance outweigh the perceived benefits (Timmins, 2012). The existing literature documents a strong relationship between health insurance status and health care utilization. In particular, insured individuals are more likely to use preventative care and less likely to be hospitalized for preventable conditions (Ayanian, et al., 2000). These findings imply that when individuals lose their health insurance coverage, they are likely to alter their health care consumption and spending (Anderson, Dobkin, and Gross, 2012).

Recent federal and state policy has aimed at decreasing the low insurance rates among young adults. Specifically, since September 2010, in the United States, the Affordable Care Act (ACA) requires plans and issuers that offer dependent coverage to make the coverage available until a child reaches the age of 26 . This was a sizeable increase over the age of 19 years, the traditional dependent coverage age cutoff in many states before the ACA. The recent literature shows that this policy has significantly increased the number of young adults that are covered by a health insurance plan (Antwi, Moriya, and Simon, 2013; Wallace and Sommers, 2015).

The explicit goal of the ACA's dependent coverage mandate was to increase the access to and affordability of medical care among young individuals. However, increasing the insurance coverage rates among young adults would also have potential welfare implications. In particular, there is likely to be societal welfare gains in having these relatively lower medical risk individuals in the insurance pool through the cross-subsidization of higher risk individuals, such as those with chronic conditions and the elderly, and keeping premiums low (Timmins, 2012). Increasing insurance coverage rates among young adults may also have private welfare gains to this group of individuals by increasing access to medical care and in turn improving health status and health related outcomes. For instance, if the ACA's dependent coverage provision only increases insurance premiums without significantly increasing access to health care, then this questions the private welfare gains from this policy. This paper mainly focuses on the private welfare effects of the ACA's dependent coverage mandate. Us-

\footnotetext{
${ }^{1}$ Before 2010, insurance coverage rates among this age group was approximately 7 percentage points lower (Kirzinger, Cohen, and Gindi, 2013).
} 
ing detailed data on insurance coverage status and health care utilization from the Medical Panel Expenditure Survey (MEPS), I first investigate the effect of the ACA on insurance coverage rates among young adults who reach the policy mandated dependent coverage age of 26 . Next, I investigate the effect of this policy on health care utilization and spending among young adults and provide the estimates of a direct relationship between health insurance coverage and health care utilization.

Individuals without health insurance coverage have different risk tolerances and medical risks than those with coverage, making causal inference difficult. To overcome this challenge, several studies exploit the quasi-experimental variation to measure the impacts of Medicare and Medicaid, the two largest public insurance programs in the United States (Dafny and Gruber, 2005; Card, Dobkin, and Maestas, 2008; Currie, Decker, and Lin, 2008). However, these studies focus on the near-elderly or the very young, both of whom are at low risk of being uninsured. On the other hand, the majority of studies that investigated the impact of the ACA's dependent coverage mandate on various outcomes relies on difference-in-differences (diff-and-diff) type models. These studies use different age ranges particularly for the control group with some including individuals up to 34 years old and find that for people ages 19 through 25, the likelihood of having employer-sponsored health insurance as a dependent rose by up to 7 percentage points, while the likelihood of having any health insurance rose by about 3 percentage points (Dillender, 2015).

In this paper, I consider the short-run effects of the ACA's dependent coverage mandate and employ an alternative identification strategy based on the age-based eligibility cutoff of the ACA's dependent coverage provision. In particular, I exploit the discrete change in insurance coverage rates at age 26 and use a regression discontinuity (RD) design to compare the outcomes of those who are slightly younger than the ACA's dependent coverage age of 26 (control group) with those who are slightly older than this cutoff age (treatment group). Since observable and unobservable characteristics of young adults are likely to be distributed smoothly across the cutoff age, the change in health insurance rates and health care utilization outcomes at this age can solely be attributed to the ACA's dependent coverage mandate. To the best of my knowledge, this is the first paper that uses a RD design to investigate the impact of the ACA's dependent coverage mandate on health care utilization and spending among young adults.

I find that under alternative model specifications, $2.5 \%$ to $5.3 \%$ of young adults lose their health insurance coverage when they turn 26. This effect is mainly due to those who lose their private insurance plan coverage and those who lose their insurance plan coverage, whose main holder resides outside of the household. I also find that the discrete drop in health insurance coverage rates at 
age 26 has negative spillover effects on office-based physician and dental visits, but does not have a significant impact on the utilization of outpatient or emergency department services. Furthermore, I find that the ACA's dependent coverage mandate does not have a significant impact on health care spending and out-of-pocket costs.

Using the estimates of discontinuity in health insurance coverage rates and health care utilization at age 26, I also estimate the direct impact of health insurance coverage on health care outcomes. I find that those who are covered under a health insurance plan have 73.5 percentage points higher probability of visiting an office-based physician and 42.9 percentage points higher probability of visiting a dentist than those who are not covered by an insurance plan. This impact is mainly driven by males, whites, and employed.

The rest of this paper proceeds as follows. The next section describes previous research on health insurance coverage and health care utilization. Section 3 describes the data, while section 4 outlines the econometric framework. Section 5 presents the results for alternative samples. Section 6 provides a discussion of policy implications and concludes.

\section{Background and review of the literature}

The vast majority of studies investigating the relationship between health insurance coverage and medical care consumption compare insured individuals with those who are not insured and find that insured are less likely to have adverse health outcomes (Hoffman and Paradise, 2008). These studies also find that lack of insurance coverage often leads to expensive and avoidable medical treatments (Braveman et al.,1994 and Weissman, Gatsonis, and Epstein, 1992). However, findings from these studies may not represent causal effects since people who choose to purchase insurance are likely to be different in unobservable ways than those who do not, and these unobservable differences may also affect health care utilization and expenses.

In order to address this potential endogeneity problem, few studies use data from randomized insurance experiments. A well-known example is the RAND Health Insurance Experiment conducted in 1970s, which randomly assigned individuals to insurance schemes with different cost-sharing rules. Brook et al. (1983) and Keeler (1992) find that compared with those with free access to health care, cost-sharing led to less total spending on medical care and fewer physician visits. Similarly, Brook et al (1984) and Newhouse (2004) find that a high-deductible health plan considerably reduced hospital admissions relative to a free plan. Another well-known example is the unique lottery in Oregon that 
allowed low-income adults to apply for Medicaid. Finkelstein et al. (2012) report that in the year after random assignment, the treatment group selected by the lottery was about 25 percentage points more likely to have insurance than the control group that was not selected.

Several other studies address the endogeneity of insurance coverage using quasi-experimental data. One group of these studies evaluates Medicaid expansions and changes in eligibility rules for Medicaid and Medicare. For instance, Dafny and Gruber (2005) find that relaxing Medicaid restrictions for low-income children increased hospital admissions and physician visits and decreased the mortality rates. Similarly, McWilliams et al. (2003) and Card, Dobkin, and Maestas (2008, 2009) find that the introduction of Medicare at age 65 leads to a substantial increase in health care consumption. One limitation of these studies is that public insurance programs target specific groups of people (young children, the very low income, and the elderly) and do not aim at increasing the insurance coverage rates among young adults, who have different medical risks and may be less likely to be insured. Moreover, many individuals who gain insurance through public insurance programs are often insured beforehand, making it difficult to isolate the causal effect of having insurance coverage (Anderson, Dobkin, and Gross, 2012).

Starting from September 23, 2010, The ACA requires health insurance plans and issuers that offer dependent coverage to make the coverage available until a child reaches the age of 26 . For plan or policy years beginning on or after this date, all health insurance plans and issuers were required to give children who qualify an opportunity to enroll that continues for at least 30 days regardless of whether the plan or coverage offers an open enrollment period. Both married and unmarried children qualify for this coverage. This law applies to all plans in the individual market and to new employer plans. It also applies to existing employer plans unless the adult child has another offer of employer-based coverage (such as through his or her existing job). However, after 2014, children up to age 26 were allowed to stay on their parent's employer plan even if they have another offer of coverage through their employer. Studies that investigated the early effects of the ACA find significant increases in health insurance coverage rates among young adults. For instance, using diff-and-diff methodology, Antwi, Moriya, and Simon (2013) compare health insurance coverage rates of 19-25 year olds with 16-18 and 27-29 year olds and find that young adults were 30 percent more likely to be on their parents' employer policies after the implementation of the ACA on September 2010, compared to the time period before the enactment of the law. Antwi, Moriya, and Simon (2014) find that after the implementation of the ACA's dependent coverage mandate, compared to those who are 27-29 years old, treated young adults who are 19-25 years old increased their inpatient visits by 3.5 percent. Using 
a similar methodology, Cantor et al. (2012) find that the mandate increased health insurance coverage for young adults across all racial groups and regardless of employment status. Chua and Sommers (2014) find that the provision is associated with a reduction in out-of-pocket medical expenses but does have a significant impact on health care use. In a recent paper, Barbaresco, Courtemanche, and Qi (2015) estimate diff-and-diff models with 23-25 year olds as the treatment group and 27-29 year olds as the control group. They find that the dependent coverage provision increased the probabilities of having health insurance, a primary care doctor, and excellent self-assessed health, while reducing body mass index. They also find that the mandate increased risky drinking but did not lead to any significant increase in preventive health care utilization.

Although the existing studies on the effects of the ACA's dependent coverage mandate rely on diff-and-diff type models, they use different age ranges particularly for the control group with some including individuals up to 34 years old (Sommers and Kronick, 2012; Sommers et al.,2013; Chua and Sommers, 2014). Slusky (forthcoming) and Barbaresco, Courtemanche, and Qi (2015) argue that different age groups are often subject to different economic shocks. Using data from Current Population Survey (CPS) and Survey of Income and Program Participation (SIPP), Slusky (forthcoming) runs placebo tests using data from before the mandate and artificial "treatment" dates and show that the diff-and-diff regressions with these dates also produce statistically significant effects of the ACA on labor market outcomes long before the ACA was implemented. He argues that the effects that have been attributed to the ACA actually reflect overall dynamics in the age-structure of the labor market and reducing the age bandwidth yields more reliable estimates.

In terms of methodology, this paper is similar to few recent papers that focus on the pre-ACA period. Before the ACA required all employers to provide health insurance to employees' children until the age of 26, many private health insurance contracts covered dependents through age 19 or 23 if they are a full time student (Anderson, Dobkin, and Gross, 2012; Anderson, Dobkin, Gross, 2014; Cardella and Depew, 2014). ${ }^{2}$ Recently, few studies find that before the introduction of the ACA, health insurance coverage rates among young adults exhibited a discrete change at these cutoff ages. In particular, these studies find a 5 to 8 percentage point reduction in the probability of having health insurance coverage at age 19 (Anderson, Dobkin, and Gross, 2012; Cardella and Depew, 2014) and a 1.5 percentage point decrease in the probability of having health insurance coverage at age 23 (Anderson, Dobkin, Gross, 2014). They also show that the discrete change in health insurance

\footnotetext{
${ }^{2}$ Even if employers choose to offer coverage to children over 19 or 23 years old, there is a strong disincentive for parents to keep them on their plans because it would count as a taxable benefit given their children no longer qualify as dependents under the federal tax law (Levine, McKnight, and Heep, 2011).
} 
coverage status at these ages leads to significant reductions in self-reported health status, emergency department and hospital visits, and inpatient hospital admissions. Furthermore, Yörük (2015) shows that the discrete change in health care utilization at age 19 is not due to the potential changes in in risk taking behavior. In contrast to these papers, in this paper, I focus on the post-ACA period and use a different age-based eligibility cutoff mandated by the new policy.

This paper is most comparable to Dillender (2015), who exploits the discrete change in insurance coverage rates at age 26 to investigate the effect of health insurance coverage on workers' compensation filing using data from Texas. However, in contrast to Dillender (2015), this paper uses national data from the MEPS, which provides very detailed information on health insurance coverage and related outcomes and estimates the effect of the ACA's dependent coverage mandate on different outcomes, i.e., different types of health care use and health care spending.

\section{Data}

The MEPS is a survey of families and individuals, their medical providers (doctors, hospitals, pharmacies, etc.), and employers across the United States. In addition to very detailed information on health insurance coverage status, the MEPS also contains information on the specific health services that Americans use, how frequently they use them, the cost of these services, and how they are paid for. The MEPS has two major components: the Household Component and the Insurance Component. In this paper, I use data from the Household Component, which provides data from individual households and their members. To supplement and verify the accuracy of information received from individuals, the MEPS also obtains information from medical providers, which individuals reported to have visited, such as the date of visit, reason for visit, diagnosis, and payment information (Medical Provider Component of the MEPS). Each individual is interviewed five times over two full calendar years. Individuals who leave their original family unit are followed and remain in the survey. Every year, a new panel of approximately 15,000 individuals is added to the survey. Therefore, two panels overlap at any given point in time, resulting in roughly 30,000 individuals being interviewed each year.

Since the ACA's dependent mandate was enforced after September 2010, I use 2011, 2012, and 2013 waves of the MEPS. I restrict my sample to those who are at most 3 years younger or older than age 26 cutoff (23-29 year olds) but also consider alternative age bandwidths such as 1 or 2 years as a 
robustness check. ${ }^{3}$ Each respondent is asked about her insurance coverage status, the type (public, private, etc.) of insurance that she held, and her health care use in each calendar month during the two year period that she remained in the survey. Therefore, for each respondent, there are up to 24 observations for each outcome and more than 103,000 observations for the full sample.

In order to investigate the potential change in insurance coverage status of individuals upon turning 26 , I create four binary variables representing coverage in a given month. These are whether the respondent is covered under any type of medical insurance plan (private or public); whether the respondent is covered under a private insurance plan; whether the respondent is covered under a public insurance plan; and whether the respondent is covered under a medical insurance plan, whose main holder resides outside of the respondent's household. This last outcome is particularly useful to test the effects of the ACA's dependent coverage mandate on those who do not live with their parents but are covered under their parents' insurance plan until they turn 26. In Table 1, I provide the summary statistics for these variables. Approximately $68 \%$ of 23-29 year olds have health insurance, with older respondents being slightly less likely (67\%) compared with the younger respondents (69\%). Similarly, compared to those who are older than 26, younger respondents are more likely to have a private insurance (59\% vs. 56\%). However, the public insurance coverage rates of these two groups are virtually the same (12\%). Approximately $7 \%$ of $23-29$ year olds are covered under a medical insurance whose main holder resides outside the household, with older respondents considerably less likely $(0.5 \%)$ compared with younger respondents $(13 \%)$.

As an indicator of non-urgent medical care consumption, I focus on office-based physician visits, outpatient visits, and dental visits. ${ }^{4}$ Office visits include non-emergency medical care that occurs in a variety of settings such as doctors' offices, medical centers, and laboratory or x-ray facilities. Outpatient visits cover variety of situations in which a patient is not hospitalized overnight but visits a hospital, clinic, or associated facility for diagnosis or treatment. For dental care, I consider visits to general dentists, dental hygienists, and orthodontists. For each respondent, medical care utilization at the month level is the focus of the empirical analysis. In particular, I consider whether an individual

\footnotetext{
${ }^{3}$ Since information on the exact birth date is not available, it is not possible to determine the exact date of turning 26 for each respondent. Therefore, it is impossible to determine the treatment status of a respondent for the month that she turns 26. In order to address this problem, I exclude the month that each respondent turns 26 from the sample (when the running variable, i.e., the number of months before or after the 26 th birthday, is equal to 0 ).

${ }^{4}$ The MEPS also contains information on prescribed medicines, hospital inpatient stays and other medical expenses. Date of utilization at the month level is not available for prescribed medicines and other medical expenses. On the other hand, very few people who are around 26 have a record of an inpatient stay, which makes an empirical analysis impractical for this type of health care use.
} 
use a particular type of service (a binary indicator of health care utilization at a given month), the number of visits per month, total expenditures for each type of care (the sum of out-of-pocket and insurance amounts paid, including the third party payers), and out-of-pocket cost for each service. Total expenditures and out-of-pocket costs are adjusted for inflation and expressed in 2013 dollars. Table 2 reports the summary statistics for these variables. Approximately $15 \%$ of young adults have an office-based physician visit in a given month, $4 \%$ have a dental visit, and $1 \%$ use outpatient services. Compared to those who are younger than 26, those who are relatively older are slightly more likely to use these services. In general, monthly medical care spending is quite low for young adults, with average out-of-pocket cost being $\$ 9.2$ for office visits ( $\$ 62.5$ for those with at least one visit), $\$ 1.4$ for outpatient visits ( $\$ 125.6$ for those with at least one visit), and $\$ 5.6$ for dental visits $(\$ 145.4$ for those with at least one visit).

The MEPS also collects detailed information on emergency department visits. Table 2 shows

that approximately $1.5 \%$ of young adults use emergency health care in a given month. Compared to relatively older individuals, those who are younger than 26 are slightly more likely to have an emergency department visit, but their out-of-pocket costs are lower. On average, young adults spend $\$ 2.7$ per month for emergency room visits (\$178.9 for those with at least one visit).

\section{Methodology}

The relationship between health insurance coverage and health care utilization and expenses can be expressed by the following reduced form model:

$$
Y_{i}=\beta_{1}^{\prime} \mathbf{X}_{i}+\alpha_{1} \operatorname{Ins}_{i}+u_{i}
$$

In equation (1), $Y_{i}$ is the outcome variable (health care utilization, health care expenses, or out-ofpocket costs) for individual $i$, Ins $_{i}$ is a binary variable representing health insurance coverage status, and $u_{i}$ denotes the unobservable factors affecting the outcome variable. The set of control variables, $\mathbf{X}_{i}$, includes family size, log of household income, whether the respondent reported excellent health status, and a set of binary variables controlling for gender, race, educational attainment, and marital and employment status of the respondent. The coefficient of interest is $\alpha_{1}$, which is the estimated impact of health insurance coverage status on the relevant outcome variable. There may be several unobservable individual characteristics such as different attitudes towards risk or medical conditions that are correlated with both insurance coverage status and outcome variables. Therefore, insurance 
take-up is likely to be endogenous and it is not possible to get a consistent estimate of $\alpha_{1}$ using equation (1).

The identification strategy in this paper relies on the assumption that those who are slightly younger or older than 26 have very similar observable and unobservable characteristics. However, due to the ACA's dependent coverage mandate, compared to those who are slightly older than 26 (who are at risk of losing their insurance coverage), those who are slightly younger than 26 are more likely to be covered under a health insurance plan. Since individuals have no control over their age, the ACA's dependent coverage mandate creates an exogenous variation in health insurance coverage status at the cutoff age of 26. I exploit this variation and use a RD design to estimate the relationship between health insurance coverage and health care utilization and expenses. ${ }^{5}$ I first estimate the following RD model, which shows the effect of turning 26 on health insurance coverage status:

$$
\text { Ins }_{i}=\beta_{2}^{\prime} \mathbf{X}_{i}+\alpha_{2} T_{i}+f\left(a g e_{i}\right)+v_{i} .
$$

In this equation, the binary treatment variable is denoted by $T_{i}$ and is equal to 1 if the respondent is at least 26 years old in a given month and 0 otherwise and the coefficient $\alpha_{2}$ is the estimated effect of turning 26 on health insurance coverage status. A smooth function of age profile, $f\left(a g e_{i}\right)$, is the forcing variable in the context of RD design. Since, information on the birth month and year of each respondent is available in the MEPS, it is possible to calculate the difference between the date of health care utilization and the respondent's $26^{\text {th }}$ birthday in months. Therefore, for each respondent, the variable $a g e_{i}$ represents the number of months before or after the $26^{\text {th }}$ birthday. Modelling the smooth function of the forcing variable correctly is one of the main problems in implementing the RD design. In order to test the robustness of my results under alternative parametric model specifications, I estimate several different models that contain the first, second, or third order polynomial of the forcing variable, which is also fully interacted with the treatment variable. The age profile for alternative parametric models with different degrees of polynomials can be expressed as:

$$
f\left(a g e_{i}\right)=\sum_{j=1}^{k} \delta_{j} a g e_{i}^{j}+\sum_{j=1}^{k} \lambda_{j}\left(T_{i} \times a g e_{i}^{j}\right) \text { for } k=\{1,2,3\} .
$$

In the empirical analysis, I restrict my sample to all observations in which the respondent is up to 36 months (3 years) younger or older than the cutoff age of $26(|a g e| \leq 36)$. Since the RD estimates may be sensitive to the selection of this bandwidth, I report results for alternative choices of bandwidths,

\footnotetext{
${ }^{5}$ Imbens and Lemieux (2008), Porter (2003), and Lee and Lemieux (2009) present a detailed discussion of the RD design and related issues.
} 
i.e., $\left|a g e_{i}\right| \leq 24$ (2 years) and $\left|a g e_{i}\right| \leq 12$ (1 year). In all models, I exclude the month that each respondent turns 26 from the sample $\left(a g e_{i}=0\right){ }^{6}$ I also use the sample weights as reported in the MEPS and cluster standard errors by the forcing variable. The identifying assumption in equation (2) is that at age 26 , the change in the insurance coverage status should be solely due to the age based cutoff and other observable and unobservable characteristics of respondents that may affect insurance coverage should not exhibit a discrete change around the $26^{\text {th }}$ birthday. This is a partially testable assumption. In the next section, I provide the results from a formal test which shows that control variables vary smoothly around the $26^{\text {th }}$ birthday. Therefore, they have little effect on the estimates of the discontinuity and serve mainly to increase the precision of the estimates.

It is also possible to estimate equation (2) using non-parametric estimators. For non-parametric models, following Hahn, Todd, and van der Klaauw (2001) and Porter (2003), I use local linear regressions to estimate the left and right limits of discontinuity at age 26 . I estimate this in one step using triangular kernel which has been shown to be boundary optimal by putting more weight on observations closer to the cutoff point (Cheng, Fan, Marron, 1997). The remaining estimation issue for the non-parametric models is the selection of appropriate bandwidth. Since the RD is identified only at the discontinuity, one needs to try to balance the goals of staying as local to the cutoff point at age 26 as possible while ensuring that there are enough data to yield informative estimates. In all non-parametric models, I use the bandwidth selection procedure that is proposed in a recent paper by Imbens and Kalyanaraman (2012).

In order to estimate the effect of the ACA's dependent coverage mandate on health care expenses and utilization, I plug in equation (2) to equation (1). The resulting reduced form model can be expressed as:

$$
Y_{i}=\beta_{3}^{\prime} \mathbf{X}_{i}+\alpha_{3} T_{i}+f\left(a g e_{i}\right)+\varepsilon_{i},
$$

where $\alpha_{3}$ estimates the change in relevant outcome variable at age 26. Similar to equation (2), using alternative bandwidths and functional forms, I estimate this model both parametrically and non-parametrically.

Using the estimates of discontinuity at the cutoff age of 26 , I also provide the estimates of the direct impact of health insurance coverage on health care outcomes (equation (1)). Following Timmins (2012), Cardella and Depew (2014), and Yörük (2015), this method relies on using the discrete change in the probability of having health insurance coverage at age 26 as an instrument for the health

\footnotetext{
${ }^{6}$ As mentioned before, since the MEPS does not report the exact birth date of the respondents, it is not possible to determine to treatment status for these individuals.
} 
insurance coverage status in the first stage. The main assumption in this instrumental variable (IV) method is that the probability of having health insurance changes significantly at age 26 but at this cutoff age, unobserved determinants of health care utilization and expenses are not affected.

\section{Results}

\subsection{Health insurance coverage}

In Table 3, I report the RD estimates of the change in health insurance coverage status at age 26 under alternative parametric and non-parametric models and bandwidth choices. The estimates suggest that $2.5 \%$ to $5.3 \%$ of the respondents lose their health insurance coverage when they turn 26 . This effect is highly significant and mainly driven by those who lose their private insurance plan coverage and those who lose their insurance plan coverage, whose main holder resides outside of the household. In particular, under alternative specifications, I find that at age 26, the probability of being covered under a private insurance plan goes down by 2.2 to 6.3 percentage points and the probability of being covered under a health care plan whose main holder resides outside of the household goes down by 3.4 to 6.6 percentage points. On the other hand, the effect of turning 26 on the probability of having a public insurance plan is relatively limited and also the sign and magnitude of its estimate is sensitive to choice of alternative models. Figure 1 illustrates these findings. In each figure, I plot the mean of the outcome variables (the probability of being covered under alternative insurance plans) for one month intervals two years before and after the $26^{\text {th }}$ birthday. The solid lines are the first and second order polynomials fitted on individual observations on both sides of the age-26 cutoff as reported in the first two specifications of Table 3 for an age bandwidth of 24 months. Panels A, B, and D of Figure 1 clearly show the discrete drop in health insurance coverage rates at age 26 under any plan, a private plan, and a plan whose main holder resides outside of the respondent's household.

The reliability of these RD estimates depends on several implicit assumptions, some of which are testable. I present the relevant tests in the Appendix. First, although unlikely, those who are slightly older than 26 may be less likely to participate the MEPS. If this is the case, the density of the forcing variable may exhibit a discrete change at age 26, which would bias the RD estimates. However, Figure A1 shows that the number of observations around the $26^{\text {th }}$ birthday is smoothly distributed and there is no evidence to suggest a potential manipulation of the forcing variable.

Another implicit assumption behind the RD design is that the change in the insurance coverage status should be solely due to the age-based cutoff and other observable and unobservable character- 
istics of respondents that may affect insurance coverage should not exhibit a discrete change around the $26^{\text {th }}$ birthday. This assumption is likely to hold since most obvious confounders are unlikely to exhibit a discrete change at the cutoff age. For instance, factors related to income, marital status, or getting an advanced degree should not bias the estimates since they are not directly related to certain birthdays. Graduations, for example, generally occur in January or June, but $26^{\text {th }}$ birthdays are distributed throughout the year. Therefore, probability of having an advanced degree should not change discontinuously in the month following an individual's $26^{\text {th }}$ birthday. The results presented in Table 3 also support this hypothesis. Parametric models estimated with and without control variables yield similar estimates. This suggests that the observable characteristics of the respondents do not exhibit a discrete change at age 26. I further test the possibility that other changes in observable characteristics of individuals may occur at their $26^{\text {th }}$ birthday. In the $\mathrm{RD}$ context, this is equivalent to testing the smoothness of all control variables around the cutoff age. Hence, I estimate equation (2) separately for all control variables using a parametric model that contains a quadratic polynomial of the forcing variable, which is also fully interacted with the treatment variable. For all control variables, the coefficient on the treatment variable was insignificant, which suggests that control variables are smoothly distributed across the cutoff age. ${ }^{7}$ Figure A2 also illustrates this result for selected covariates.

Finally, some insurers provide extended dependent coverage until the end of the year in which the individual turn 26. Since the MEPS does not provide plan specific information, it is not possible to determine the respondents who were actually covered under a plan that provides this option. For comparison purposes, I assume that all respondents who benefited from the ACA's dependent coverage provision was covered under a plan that provides an extended coverage until the end of the plan year. Therefore, the cutoff month becomes the December of the year that the respondent turns 26. Although not reported here, under this assumption, the RD estimates suggest that $5.6 \%$ to $6.6 \%$ of the respondents lose their health insurance coverage until the end of the year in which they turn 26. These estimates are highly significant and larger than my original estimates. Therefore, while these estimates can be interpreted as the upper bound of the true effect, it is possible that my original results underestimate the effect of the ACA's dependent coverage mandate on health insurance coverage rates.

\footnotetext{
${ }^{7}$ Although not reported here to save space, estimation results are available from the author upon request.
} 


\subsection{Health care utilization}

I first investigate on the impact of the ACA's dependent coverage mandate on the utilization of nonurgent medical services. Table 4 reports the RD estimates of the change in office-based physician visits at age 26 . The results suggest that the probability of an office visit goes down by 1.4 to 3.6 percentage points when young adults turn 26. This effect is highly significant under all specifications with the exception of the parametric model that is estimated using a cubic polynomial of the forcing variable and an age bandwidth of 12 months. Similarly, the number of office visits per month decreases by 0.03 to 0.09 points at age 26 . This effect is statistically significant under majority of specifications and relatively large given that the mean of this variable is approximately 0.25 . The change in total payments and out-of-pocket costs for office visits at the $26^{\text {th }}$ birthday is also negative and relatively large. However, statistical significance and the size of these estimates are quite sensitive to model selection. Figure 2 further illustrates these results and shows the discrete change in the probability and number of office visits at age 26 .

Table 5 and Figure 3 show that the discrete change in health insurance coverage at the $26^{\text {th }}$ birthday does not have a statistically significant impact on outpatient visits. In particular, although the magnitude of the estimates suggest that young adults become less likely to use outpatient services when they turn 26, this effect is statistically insignificant under all specifications. Similarly, the results for the number of visits, total payments, and out-of-pocket costs are mostly insignificant and the sign and the magnitude of the estimates for these outcomes are not robust under alternative specifications.

In Table 6 and Figure 4, I report the RD estimates of the change in dental visits due to ACA's dependent coverage mandate. The results suggest that the probability of using dental services goes down by 1 to 2.1 percentage points when young adults turn 26. Furthermore, young adults tend to visit dental offices 0.014 to 0.03 times less per month at this cutoff age. Given the mean of the relevant outcome variables, these effects are considerably large and statistically significant under most specifications. However, the discrete drop in health insurance coverage rates at age 26 does not have a significant impact on total payments and out-of-pocket costs for dental visits.

The existing literature suggests that the uninsured individuals are more likely to seek urgent care than the insured (Kwack, et al. 2004). It is also commonly assumed that uninsured patients visit the emergency department for non-urgent problems and contribute to crowding of emergency departments (Newton, et al. 2008). I investigate the impact of the ACA's dependent coverage mandate on emergency department visits and report the results in Table 7 and Figure 5. The results 
suggest that the probability of visiting the emergency department goes down by approximately 0.2 percentage points when young adults turn 26. This effect is considerable but in general, statistically insignificant under alternative specifications. Similarly, the effect of the ACA on the number of emergency room visits is statistically insignificant. The results show that changes in total payments and out-of-pocket costs for emergency room visits at the $26^{\text {th }}$ birthday are also mostly negative and relatively large. However, statistical significance and size of these estimates are quite sensitive to the selection of alternative models.

It is possible that young adults who are likely to lose their health insurance coverage at their $26^{\text {th }}$ birthday, anticipate this before hand and increase their health care consumption just before turning 26. This could generate a discrete drop in reported levels of health care utilization at age 26 even is there is no true change in actual behavior. In order to investigate this possibility, I compare health care utilization among young adults who are about to become 26 with those who are slightly younger than 25 or 27 . One could expect that compared with those who are slightly younger than 25 or 27 , those who are slightly younger than 26 would be more likely to use health care since the ACA's dependent coverage mandate should not affect the insurance coverage rates around these alternative age cutoffs. However, Figure A3 in the Appendix show that the probability of using alternative health care services up to six months before the $25^{t h}, 26^{\text {th }}$, and $27^{\text {th }}$ birthdays exhibit similar trends. Therefore, there is no evidence that young adults anticipate the effects of the ACA's dependent coverage provision and significantly alter their health care consumption just before their $26^{\text {th }}$ birthday.

\subsection{Alternative samples}

There exists an extensive literature which documents that individuals that belong to different demographic groups differ in their attitudes towards risk. ${ }^{8}$ These differences may also affect health care decisions. In order to investigate the impact of the ACA's dependent coverage mandate on alternative demographic groups, I estimate parametric RD models for different types of insurance coverage status using a quadratic polynomial of the forcing variable that is also fully interacted with the treatment variable. $^{9}$ The results reported in Table 8 shows that the ACA has similar effects on health insurance coverage rates among males and females. Approximately $3 \%$ of both groups lose their health insurance coverage when they turn 26. Compared with whites, the impact of the ACA on blacks is more pronounced. Approximately, 5.1\% of blacks lose their health insurance at age 26, whereas only

\footnotetext{
${ }^{8}$ See, for example, Booth and Nolen (2012) and Powell and Ansic (1997).

${ }^{9}$ Alternative parametric and non-parametric models yield comparable results.
} 
$2.2 \%$ of whites lose health insurance coverage at the same age cutoff. One would expect that the ACA's dependent coverage provision is less likely to affect employed young adults since before 2014, if the adult child had another offer of employer-based coverage, she may not allowed to stay on her parent's insurance plan. Table 8 shows that compared with $4.3 \%$ of unemployed young adults, $3.6 \%$ of employed young adults lose their health insurance coverage due to the ACA. On the other hand, the effect of the ACA's dependent coverage mandate on married young adults is relatively small and statistically insignificant.

Rules governing public insurance may also affect the insurance coverage rates after the introduction of the ACA. The ACA created a national Medicaid minimum eligibility level of $133 \%$ of the federal poverty level (FPL) for nearly all Americans under age 65. This Medicaid eligibility expansion went into effect on January 1, 2014 but states were allowed to choose to expand coverage with Federal support anytime before that date. The MEPS has detailed information on income and categorizes individuals into one of the five income groups: the poor (100\% or less of the FPL), the near poor $(100-124 \%$ of the FPL), low income (125 - 199\% of the FPL), middle income (200 - 399\% of FPL), and high income ( $400 \%$ or more of FPL). Table 8 shows that the effect of the ACA's dependent coverage provision on poor and the near poor was statistically insignificant. This is not surprising since most of the change in insurance coverage at age 26 comes from a decline in private insurance, with very little change in public insurance. In fact, private insurance coverage rates for this group significantly decreases at age 26 . On the other hand, the ACA's impact on low income and middle or high income young adults is considerable. Table 8 shows that $7.5 \%$ of low income and $2.5 \%$ of middle or high income young adults lose their health insurance coverage at age 26 .

The main results suggest that the ACA's dependent coverage mandate's main impact was on the probability and number of office-based physician and dental visits. In Tables 9 and 10, I test the robustness of this result for alternative subsamples. Table 9 shows that the change in the probability of office-based physician and dental visits at age 26 is mainly driven by the change in male's health care use behavior. Compared with blacks, although whites are less likely to lose their coverage when they turn 26, they are more likely to change their health care behavior. In particular, at age 26, the probability of office-based physician visits goes down by $2.9 \%$ for whites, whereas at this particular age, blacks do not significantly change their tendency to visit an office-based physician. Similarly, although the ACA's dependent coverage provision is more likely to change the insurance coverage rates among unemployed, employed young adults are more likely to change their health consumption. Table 9 shows that employed young adults are 2.3 percentage points less likely to visit an office-based 
physician and 1.5 percentage points less likely to visit a dentist at age 26 , while this age cutoff does not seem to have a significant impact on the office or dental visits of unemployed young adults. Table 9 also shows that married respondents are 4.5 percentage points less likely to visit a physician, 0.8 percentage points less likely to visit an emergency department, and 1.6 percentage points less likely to visit a dental office at age 26. Furthermore, compared with low income and middle or high income respondents, poor or near poor respondents are more likely to change their health care use behavior due to ACA's dependent coverage provision. In particular, this group of young adults are 3.7 percentage points less likely to visit a physician and 1.5 percentage points less likely to visit a dental office once they turn 26.

In Table 10, I run similar robustness checks for the number of medical visits for different types of health care utilization. The ACA's dependent coverage mandate has a significant impact on the number of office-based physician visits for males and married young adults. Except for females, blacks, and unemployed, the number of dental visits significantly decreases for all subsamples at age 26. On the other hand, as for the full sample, the change in the number of outpatient and emergency department visits at age 26 is relatively small and mostly statistically insignificant for alternative groups of young adults.

The main findings suggest that for the full sample, the ACA's dependent coverage mandate does not have significant impact on total health care spending and out-of-pocket costs. However, most of the young adults occasionally use health care. In Tables 11 and 12, I investigate the effects of the ACA among those who reported having at least a single medical visit in a given month. Given there is likely to be heterogeneity in medical care use across young adults, this conditional effect may be more informative for understanding how heavier users of medical care are affected by insurance loss. Table 11 shows that for those who used health care services at least once at a given month, total spending for outpatient visits increases by approximately $\$ 1379$. This effect is marginally significant and mainly due to the increase in total spending of females. However, compared to other health care services considered, young adults are far less likely to use outpatient services. Therefore, this result should be interpreted with caution due to small sample size. On the other hand, total spending for office visits for blacks and unemployed increases by approximately $\$ 185$ at age 26 , while total spending for emergency department visits increases by $\$ 466$ for poor and near poor at the same age cutoff.

Table 12 replicates the same analysis for out-of-pocket costs. Out-of-pocket costs for outpatient visits for blacks increases by approximately $\$ 758$ at age 26 . Although this impact is highly significant, 
it is based on a very small sample size and therefore, may not be very informative. The estimation results for the remaining outcomes are statistically insignificant and in general, their magnitudes are relatively small.

\subsection{The effect of health insurance on health care utilization}

Using the estimates of the discontinuity in health insurance coverage rates at age 26, it is also possible to estimate the direct impact of the health insurance coverage status on health care utilization among young adults. This IV method relies on using the discrete change in the probability of having health insurance coverage at age 26 as an instrument for the health insurance coverage status in the first stage. ${ }^{10}$ In Tables 13 and 14, I present the results from these models. Table 13 shows that those who are covered under any type of insurance plan have 73.5 percentage point higher probability of visiting a physician and 42.9 percentage point higher probability of visiting a dentist than those who are not covered by a health insurance plan. This impact is mainly driven by males, whites, employed, and poor or near poor.

Table 14 shows that those who are covered by a health insurance plan visit dental office 0.66 times more per month than the uninsured. This effect is highly significant. Similarly, health insurance coverage has a significant and positive impact on the number of dental visits for the majority of subsamples with the exceptions of black, unemployed, and married young adults.

\section{Conclusion}

Most of the uninsured in the United States are young adults. Understanding this population's reaction to changes in health insurance status are essential to evaluate public policies that are aimed at increasing access to health care. Using detailed data from the MEPS and a RD design, this paper evaluates the impact of the ACA' dependent coverage mandate, a recently introduced federal policy, on health insurance coverage rates and health care utilization among young adults. The results reveal that $2.5 \%$ to $5.3 \%$ of young adults lose their health insurance coverage when they turn 26 , the cutoff age mandated by the ACA's dependent care provision. This effect is mainly driven by those who lose their private insurance plan coverage and those who lose their insurance plan coverage, whose main

\footnotetext{
${ }^{10}$ In this context, the IV estimate is actually the ratio of the discontinuity in a particular health care use outcome at age 26 to the discontinuity in the probability of having health insurance at the same age cutoff. However, since the sample sizes for health insurance coverage and health care use outcomes are slightly different, this ratio is quite similar but not precisely the same as the IV estimate.
} 
holder resides outside of the household. The results also suggest that the discrete change in health insurance coverage rates significantly decreases office-based physician and dental visits, but does not have a significant effect on the utilization of outpatient or emergency department services. Using the estimates of discontinuity in health insurance coverage rates and health care utilization at age 26, I also estimate the direct impact of health insurance coverage on health care outcomes and find that those who are covered under a health insurance plan have 73.5 percentage points higher probability of visiting an office-based physician and 42.9 percentage points higher probability of visiting a dentist than those who are not covered by an insurance plan.

This paper provides direct evidence that ACA's dependent coverage mandate increased both insurance coverage rates and office-based physician and dental visit rates of individuals in their early twenties. Since the MEPS does not contain information on the state of residence, it is not possible to estimate the effect of the policy for states that have already enacted private coverage extension laws. However, Levine, McKnight, and Heep (2011) argue that modest increases should occur even in those states because state insurance regulations do not apply to larger companies that self-insure.

Due to the nature of the RD design, the findings of this paper represent the short-run effects of the ACA's dependent coverage provision. The short-run effects may be different than the long-run effects since individuals may shift the timing of health care visits across the age 26 threshold. In particular, when losing insurance, individuals may be more likely to use health care services shortly before coverage expires. Alternatively, when gaining insurance, individuals may postpone health care until shortly after coverage begins. However, I find no evidence that young adults anticipate the effects of the ACA's dependent mandate and significantly alter their health care consumption just before their $26^{\text {th }}$ birthday. Furthermore, previous literature also documents that there is little evidence that individuals shift the timing of health care visits in anticipation of gaining or losing insurance coverage. ${ }^{11}$

Finally, since all RD designs estimate local treatment effects, the results of this paper apply to individuals close to their $26^{\text {th }}$ birthday and cannot be generalized to whole population. Nevertheless, adults in their twenties, the age group to which the findings of this paper likely to apply, represent a substantial share of the uninsured population (Anderson, Dobkin, and Gross, 2012). Furthermore, in addition to being focused on a particular age group, the RD estimates are also specific to young adults who lose coverage because they age out of their parents insurance. These individuals may be different from the typical young adult. However, the findings of this paper should still provide useful

\footnotetext{
${ }^{11}$ See, for example, Gross (2010), Card, Dobkin, and Maestas (2008), Long, Marquis, and Rodgers (1998).
} 
information to policy makers since the results reveal that the decrease in health insurance coverage rates at age 26 is mainly due to those who lose their insurance plan coverage, whose main holder resides outside of the household. These are the individuals that are likely to gain coverage under the ACA's dependent coverage provision.

\section{References}

[1] Anderson, M., C. Dobkin, and T. Gross, 2012, The effect of health insurance coverage on the use of medical services, American Economic Journal: Economic Policy, 4, 1-27.

[2] Anderson, M., C. Dobkin, and T. Gross, 2014, The effect of health insurance on emergency department visits: Evidence from an age-based eligibility threshold, Review of Economics and Statistics, 96, 189-195.

[3] Ayanian, J.Z., et al., 2000, Unmet health needs of uninsured adults in the United States, Journal of the American Medical Association, 284, 2061-2069.

[4] Barbaresco, S., C.J. Courtemanche, and Y. Qi, 2015, Impacts of the affordable care act dependent coverage provision on health-related outcomes of young adults, Journal of Health Economics, 40, 54-68.

[5] Booth, A.L. and P. Nolan, 2012, Gender differences in risk behavior: Does nurture matter?, Economic Journal, 122, 56-78.

[6] Braveman, P., et al., 1994, Insurance-related differences in the risk of ruptured appendix, New England Journal of Medicine, 331, 444-449.

[7] Brook, R.H., et al., 1983, Does free care improve adults' health? Results from a randomized controlled trial, New England Journal of Medicine, 309, 1426-1434.

[8] Antwi, Y.A., A. Moriya, and K. Simon, 2013, Effects of federal policy to insure young adults: Evidence from the 2010 affordable care act's dependent-coverage mandate, American Economic Journal: Economic Policy, 5, 1-28.

[9] Antwi, Y.A., A. Moriya, and K. Simon, 2014. Access to health insurance and the use of inpatient medical care: Evidence from the affordable care act young adult mandate, NBER Working Paper No. 20202. 
[10] Card, D., C. Dobkin, and N. Maestas, 2008, The impact of nearly universal insurance coverage on health care utilization: Evidence from medicare, American Economic Review, 98, 2242-2258.

[11] Card, D., C. Dobkin, and N. Maestas, 2009, Does Medicare Save Lives?, Quarterly Journal of Economics, 124, 597-636.

[12] Cantor, J.C., et al., 2012, Early impact of the affordable care act on health insurance coverage of young adults, Health Services Research, 47, 1773-1790.

[13] Cardella, E. and B. Depew, 2014, The effect of health insurance coverage on the reported health of young adults, Economics Letters, 124, 406-410.

[14] Cheng, M.Y., J. Fan, and J.S. Marron, 1997, On automatic boundary correction, Annals of Statistics, 25, 1691-1708.

[15] Chua, K.P. and B.D. Sommers, 2014, Changes in health and medical spending among young adults under health reform, Journal of the American Medical Association, 311, 2437-2439.

[16] Currie, J., S. Decker, W. Lin, 2008, Has public health insurance for older children reduced disparities in access to care and health outcomes?, Journal of Health Economics, 27, 1567-1581.

[17] Dafny, L., and J. Gruber, 2005, Public insurance and child hospitalizations: Access and efficiency effects, Journal of Public Economics, 89, 109-29.

[18] Dillender, M., 2015, The effect of health insurance on workers' compensation filing: Evidence from the affordable care act's age-based threshold for dependent coverage, Journal of Health Economics, 43, 204-228.

[19] Finkelstein, E. et al., 2012, The Oregon Health insurance experiment: Evidence from the first year, Quarterly Journal of Economics, 127, 1057-1106.

[20] Gross, T., 2010, Using insurance before you lose it: Health care consumption at the end of coverage, Unpublished Manuscript.

[21] Hahn, J., P. Todd, and W. van der Klaauw, 2001, Identification and estimation of treatment effects with a regression-discontinuity design, Econometrica, 69, 201-209.

[22] Hoffman, C. and J. Paradise, 2008, Health insurance and access to health care in the United States, Annals of the New York Academy of Sciences, 1136, 149-160. 
[23] Imbens, G. and T. Lemieux, 2008, Regression discontinuity designs: A guide to practice, Journal of Econometrics, 142, 615-635.

[24] Imbens, G. and K. Kalyanaraman, 2012, Optimal bandwidth choice for the regression discontinuity estimator, Review of Economic Studies, 79, 933-959.

[25] Keeler, E.B., 1992, Effects of cost sharing on use of medical services and health, Journal of Medical Practice Management, 8, 317-321.

[26] Kirzinger, W.K., R.A. Cohen, and R.M. Gindi, 2013, Trends in insurance coverage and source of private coverage among young adults aged 19-25: United States, 2008-2012, NCHS Data Brief, 137, 1-7.

[27] Kwack, H., et al., 2004, Effect of managed care on emergency department use in a uninsured population, Annals of Emergency Medicine, 43, 166-173.

[28] Lee, D.S. and T. Lemieux, 2009, Regression discontinuity designs in economics, NBER Working Paper No. 02138.

[29] Levine, P.B., R. McKnight, and S.Heep, S., 2011, How effective are public policies to increase health insurance coverage among young adults?, American Economic Journal: Economic Policy, 3, 129-156.

[30] Long, S.H., M.S. Marquis, and J. Rodgers, 1998, Do people shift their use of health services over time to take advantage of insurance?, Journal of Health Economics, 17, 105-115.

[31] McWilliams, J.M., et al., 2003, Impact of medicare coverage on basic clinical services for previously uninsured adults, Journal of the American Medical Association, 290, 757-764.

[32] Newton, M.F., et al., 2008, Uninsured adults presenting to US emergency departments: Assumptions versus data, Journal of the American Medical Association, 300, 1914-1924.

[33] Porter, J., 2003, Estimation in the regression discontinuity model, Unpublished Manuscript, Harvard University, Department of Economics.

[34] Powell, M. and D. Ansic, 1997, Gender differences in risk behavior in financial decision making: An experimental analysis, Journal of Economic Psychology, 18, 605-628. 
[35] Slusky, D.J.G., forthcoming, Significant placebo results in difference-in-differences analysis: The case of the ACA's parental mandate, Eastern Economic Journal.

[36] Sommers, B.D. and R. Kronick, 2012, The affordable care act and insurance coverage for young adults, Journal of the American Medical Association, 307, 913-914.

[37] Sommers, B.D., et al., 2013, The affordable care act has led to significant gains in health insurance and access to care for young adults, Health Affairs, 32, 165-174.

[38] Timmins, L., 2012, How much does health insurance matter for young adults?: Its role on primary medical care consumption, Unpublished Manuscript, Department of Economics, University of British Columbia.

[39] Weissman, J.S., C. Gatsonis, and A.M. Epstein, 1992, Rates of avoidable hospitalization by insurance status in Massachusetts and Maryland, Journal of the American Medical Association, $268,2388-2394$.

[40] Wallace, J. and B.D. Sommers, 2015, Effect of dependent coverage expansion of the affordable care act on health and access to care for young adults, Journal of the American Medical Association Pediatrics, 169, 495-497.

[41] Yörük, B.K., 2015. Health insurance coverage and risky health behaviors among young adults, CESifo Working Paper No. 5495. 
Table 1. Sample statistics: Health insurance coverage

\begin{tabular}{lccc}
\hline & Full sample & $23-26$ year olds & 26-29 year olds \\
\hline Any insurance & 0.679 & 0.688 & 0.669 \\
Private insurance & $(0.467)$ & $(0.463)$ & $(0.471)$ \\
& 0.572 & 0.585 & 0.559 \\
Public insurance & $(0.495)$ & $(0.493)$ & $(0.497)$ \\
& 0.118 & 0.118 & 0.119 \\
Holder outside of RU & $(0.323)$ & $(0.323)$ & $(0.324)$ \\
& 0.067 & 0.126 & 0.005 \\
No. of. obs. & $(0.250)$ & $(0.332)$ & $(0.072)$ \\
\hline
\end{tabular}

Notes: Sample weighted means are reported. Standard deviations are reported in parentheses. 2326 year olds include those who are up to 36 months younger than the $26^{\text {th }}$ birthday. 26-29 year olds include those who are up to 36 months older than the $26^{\text {th }}$ birthday. The month that the respondent turns 26 is excluded from the sample. 
Table 2. Sample statistics: Health care utilization

\begin{tabular}{|c|c|c|c|c|}
\hline & Prob. of visit & No. of visits & Total payment & Out of pocket cost \\
\hline \multicolumn{5}{|l|}{ Full sample } \\
\hline Office visits & $\begin{array}{c}0.147 \\
(0.354)\end{array}$ & $\begin{array}{c}0.258 \\
(0.983)\end{array}$ & $\begin{array}{c}50.63 \\
(356.55)\end{array}$ & $\begin{array}{c}9.21 \\
(81.48)\end{array}$ \\
\hline Outpatient & $\begin{array}{c}0.011 \\
(0.104)\end{array}$ & $\begin{array}{c}0.017 \\
(0.251)\end{array}$ & $\begin{array}{c}16.40 \\
(366.19)\end{array}$ & $\begin{array}{c}1.36 \\
(74.19)\end{array}$ \\
\hline Dentist & $\begin{array}{c}0.038 \\
(0.192)\end{array}$ & $\begin{array}{c}0.043 \\
(0.234)\end{array}$ & $\begin{array}{c}13.21 \\
(154.80)\end{array}$ & $\begin{array}{c}5.55 \\
(101.35)\end{array}$ \\
\hline Emergency department & $\begin{array}{r}0.015 \\
(0.123) \\
\end{array}$ & $\begin{array}{r}0.017 \\
(0.143) \\
\end{array}$ & $\begin{array}{r}15.55 \\
(236.84) \\
\end{array}$ & $\begin{array}{c}2.74 \\
(76.81) \\
\end{array}$ \\
\hline \multicolumn{5}{|l|}{$23-26$ year olds } \\
\hline Office visits & $\begin{array}{c}0.143 \\
(0.350)\end{array}$ & $\begin{array}{c}0.257 \\
(1.034)\end{array}$ & $\begin{array}{c}45.84 \\
(341.83)\end{array}$ & $\begin{array}{c}8.95 \\
(77.87)\end{array}$ \\
\hline Outpatient & $\begin{array}{c}0.011 \\
(0.102)\end{array}$ & $\begin{array}{c}0.015 \\
(0.252)\end{array}$ & $\begin{array}{c}16.42 \\
(364.16)\end{array}$ & $\begin{array}{c}1.25 \\
(39.08)\end{array}$ \\
\hline Dentist & $\begin{array}{c}0.036 \\
(0.187)\end{array}$ & $\begin{array}{c}0.042 \\
(0.230)\end{array}$ & $\begin{array}{c}11.59 \\
(126.82)\end{array}$ & $\begin{array}{c}4.46 \\
(72.02)\end{array}$ \\
\hline Emergency department & $\begin{array}{c}0.016 \\
(0.127) \\
\end{array}$ & $\begin{array}{c}0.018 \\
(0.143) \\
\end{array}$ & $\begin{array}{c}17.33 \\
(256.04) \\
\end{array}$ & $\begin{array}{c}2.69 \\
(70.91) \\
\end{array}$ \\
\hline \multicolumn{5}{|l|}{ 26-29 year olds } \\
\hline Office visits & $\begin{array}{c}0.152 \\
(0.359)\end{array}$ & $\begin{array}{c}0.260 \\
(0.927)\end{array}$ & $\begin{array}{c}55.66 \\
(371.33)\end{array}$ & $\begin{array}{c}9.48 \\
(85.10)\end{array}$ \\
\hline Outpatient & $\begin{array}{c}0.011 \\
(0.105)\end{array}$ & $\begin{array}{c}0.018 \\
(0.251)\end{array}$ & $\begin{array}{c}16.39 \\
(368.32)\end{array}$ & $\begin{array}{c}1.47 \\
(98.41)\end{array}$ \\
\hline Dentist & $\begin{array}{c}0.040 \\
(0.197)\end{array}$ & $\begin{array}{c}0.046 \\
(0.238)\end{array}$ & $\begin{array}{c}14.90 \\
(179.56)\end{array}$ & $\begin{array}{c}6.71 \\
(124.96)\end{array}$ \\
\hline Emergency department & $\begin{array}{c}0.014 \\
(0.119)\end{array}$ & $\begin{array}{c}0.016 \\
(0.144)\end{array}$ & $\begin{array}{c}13.68 \\
(214.79)\end{array}$ & $\begin{array}{c}2.80 \\
(82.55)\end{array}$ \\
\hline
\end{tabular}

Notes: Sample weighted means are reported. Standard deviations are reported in parentheses. 2326 year olds include those who are up to 36 months younger than the $26^{\text {th }}$ birthday. 26-29 year olds include those who are up to 36 months older than the $26^{\text {th }}$ birthday. The month that the respondent turns 26 is excluded from the sample. Number of observations for the full sample is 103409. Number of observations for 23-26 year olds is 51896. Number of observations for 26-29 year olds is 51513 . 
Table 3. Change in health insurance coverage at age 26: RD estimates

\begin{tabular}{|c|c|c|c|c|c|c|c|c|}
\hline & \multicolumn{2}{|c|}{ Any insurance } & \multicolumn{2}{|c|}{ Private insurance } & \multicolumn{2}{|c|}{ Public Insurance } & \multicolumn{2}{|c|}{ Holder outside of RU } \\
\hline & (1) & $(2)$ & (3) & (4) & (5) & (6) & (7) & (8) \\
\hline \multicolumn{9}{|l|}{ Bandwidth $=36$ months } \\
\hline Parametric (Linear) & $\begin{array}{c}-0.042^{* * *} \\
(0.005)\end{array}$ & $\begin{array}{c}-0.029^{* * *} \\
(0.006)\end{array}$ & $\begin{array}{c}-0.063^{* * *} \\
(0.006)\end{array}$ & $\begin{array}{c}-0.043^{* * *} \\
(0.005)\end{array}$ & $\begin{array}{c}0.016^{* * *} \\
(0.003)\end{array}$ & $\begin{array}{c}0.010^{* * *} \\
(0.003)\end{array}$ & $\begin{array}{c}-0.066^{* * *} \\
(0.004)\end{array}$ & $\begin{array}{c}-0.064^{* * *} \\
(0.003)\end{array}$ \\
\hline Parametric (Quadratic) & $\begin{array}{c}-0.026^{* * *} \\
(0.006)\end{array}$ & $\begin{array}{c}-0.025^{* * *} \\
(0.006)\end{array}$ & $\begin{array}{c}-0.028^{* * *} \\
(0.006)\end{array}$ & $\begin{array}{c}-0.025^{* * *} \\
(0.005)\end{array}$ & $\begin{array}{l}-0.004 \\
(0.004)\end{array}$ & $\begin{array}{l}-0.006 \\
(0.003)\end{array}$ & $\begin{array}{c}-0.043^{* * *} \\
(0.002)\end{array}$ & $\begin{array}{c}-0.046^{* * *} \\
(0.003)\end{array}$ \\
\hline Parametric (Cubic) & $\begin{array}{c}-0.038^{* * *} \\
(0.008)\end{array}$ & $\begin{array}{c}-0.038^{* * *} \\
(0.008)\end{array}$ & $\begin{array}{c}-0.025^{* * *} \\
(0.007)\end{array}$ & $\begin{array}{c}-0.027^{* * *} \\
(0.008)\end{array}$ & $\begin{array}{c}-0.011^{* * *} \\
(0.003)\end{array}$ & $\begin{array}{c}-0.010^{* * *} \\
(0.003)\end{array}$ & $\begin{array}{c}-0.033^{* * *} \\
(0.003)\end{array}$ & $\begin{array}{c}-0.032^{* * *} \\
(0.003)\end{array}$ \\
\hline Mean & 0.679 & 0.681 & 0.572 & 0.575 & 0.118 & 0.118 & 0.067 & 0.067 \\
\hline No. of obs. & 103034 & 102166 & 103034 & 102166 & 103034 & 102166 & 103034 & 102166 \\
\hline \multicolumn{9}{|l|}{ Bandwidth $=24$ months } \\
\hline Parametric (Linear) & $\begin{array}{c}-0.034^{* * *} \\
(0.005)\end{array}$ & $\begin{array}{c}-0.028^{* * *} \\
(0.005)\end{array}$ & $\begin{array}{c}-0.046^{* * *} \\
(0.005)\end{array}$ & $\begin{array}{c}-0.036^{* * *} \\
(0.005)\end{array}$ & $\begin{array}{c}0.004 \\
(0.003)\end{array}$ & $\begin{array}{c}0.000 \\
(0.003)\end{array}$ & $\begin{array}{c}-0.055^{* * *} \\
(0.003)\end{array}$ & $\begin{array}{c}-0.056^{* * *} \\
(0.003)\end{array}$ \\
\hline Parametric (Quadratic) & $\begin{array}{c}-0.033^{* * *} \\
(0.007)\end{array}$ & $\begin{array}{c}-0.032^{* * *} \\
(0.007)\end{array}$ & $\begin{array}{c}-0.023^{* * *} \\
(0.005)\end{array}$ & $\begin{array}{c}-0.022^{* * *} \\
(0.007)\end{array}$ & $\begin{array}{c}-0.007^{* *} \\
(0.003)\end{array}$ & $\begin{array}{c}-0.007^{* *} \\
(0.003)\end{array}$ & $\begin{array}{c}-0.036^{* * *} \\
(0.002)\end{array}$ & $\begin{array}{c}-0.035^{* * *} \\
(0.002)\end{array}$ \\
\hline Parametric (Cubic) & $\begin{array}{c}-0.041^{* * *} \\
(0.006)\end{array}$ & $\begin{array}{c}-0.038^{* * *} \\
(0.007)\end{array}$ & $\begin{array}{c}-0.033^{* * *} \\
(0.006)\end{array}$ & $\begin{array}{c}-0.029^{* * *} \\
(0.008)\end{array}$ & $\begin{array}{l}-0.000 \\
(0.004)\end{array}$ & $\begin{array}{l}-0.003 \\
(0.004)\end{array}$ & $\begin{array}{c}-0.036^{* * *} \\
(0.003)\end{array}$ & $\begin{array}{c}-0.034^{* * *} \\
(0.003)\end{array}$ \\
\hline Mean & 0.673 & 0.676 & 0.564 & 0.567 & 0.120 & 0.120 & 0.059 & 0.060 \\
\hline No. of obs. & 68815 & 68165 & 68815 & 68165 & 68815 & 68165 & 68815 & 68165 \\
\hline \multicolumn{9}{|l|}{ Bandwidth $=12$ months } \\
\hline Parametric (Linear) & $\begin{array}{c}-0.032^{* * *} \\
(0.006)\end{array}$ & $\begin{array}{c}-0.029^{* * *} \\
(0.006)\end{array}$ & $\begin{array}{c}-0.031^{* * *} \\
(0.004)\end{array}$ & $\begin{array}{c}-0.026^{* * *} \\
(0.005)\end{array}$ & $\begin{array}{c}0.002 \\
(0.003)\end{array}$ & $\begin{array}{l}-0.000 \\
(0.003)\end{array}$ & $\begin{array}{c}-0.041^{* * *} \\
(0.002)\end{array}$ & $\begin{array}{c}-0.040 * * * \\
(0.002)\end{array}$ \\
\hline Parametric (Quadratic) & $\begin{array}{c}-0.053^{* * *} \\
(0.008)\end{array}$ & $\begin{array}{c}-0.052^{* * *} \\
(0.008)\end{array}$ & $\begin{array}{c}-0.041^{* * *} \\
(0.007)\end{array}$ & $\begin{array}{c}-0.040^{* * *} \\
(0.010)\end{array}$ & $\begin{array}{c}-0.010^{* * *} \\
(0.004)\end{array}$ & $\begin{array}{c}-0.011^{* *} \\
(0.004)\end{array}$ & $\begin{array}{c}-0.040^{* * *} \\
(0.002)\end{array}$ & $\begin{array}{c}-0.039 * * * \\
(0.002)\end{array}$ \\
\hline
\end{tabular}




\begin{tabular}{|c|c|c|c|c|c|c|c|c|}
\hline Parametric (Cubic) & $\begin{array}{c}-0.046^{* * *} \\
(0.010)\end{array}$ & $\begin{array}{c}-0.051^{* * *} \\
(0.009)\end{array}$ & $\begin{array}{c}-0.029^{* * *} \\
(0.007)\end{array}$ & $\begin{array}{c}-0.035^{* * *} \\
(0.009)\end{array}$ & $\begin{array}{c}-0.019^{* * *} \\
(0.006)\end{array}$ & $\begin{array}{c}-0.019^{* *} \\
(0.007)\end{array}$ & $\begin{array}{c}-0.040^{* * *} \\
(0.002)\end{array}$ & $\begin{array}{c}-0.040^{* * *} \\
(0.002)\end{array}$ \\
\hline Mean & 0.674 & 0.678 & 0.557 & 0.560 & 0.125 & 0.126 & 0.047 & 0.047 \\
\hline No. of obs. & 35035 & 34723 & 35035 & 34723 & 35035 & 34723 & 35035 & 34723 \\
\hline Non-parametric (IK) & $\begin{array}{c}-0.033^{* * *} \\
(0.005) \\
{[19.311]}\end{array}$ & & $\begin{array}{c}-0.032^{* * *} \\
(0.003) \\
{[16.226]}\end{array}$ & & $\begin{array}{c}-0.002 \\
(0.003) \\
{[18.853]}\end{array}$ & & $\begin{array}{c}-0.041^{* * *} \\
(0.002) \\
{[14.460]}\end{array}$ & \\
\hline Controls & No & Yes & $\mathrm{No}$ & Yes & No & Yes & No & Yes \\
\hline
\end{tabular}

Notes: In all regressions, sample weights are used and standard errors are clustered by the forcing variable. Standard errors are reported in parentheses. Optimal Imbens-Kalyanaraman (IK) bandwidths are reported in brackets. The signs ${ }^{* *}$ and ${ }^{* * *}$ denote statistical significance at 5 and 1 percent. 
Table 4. Change in office visits at age 26: RD estimates

\begin{tabular}{|c|c|c|c|c|c|c|c|c|}
\hline & \multicolumn{2}{|c|}{ Prob. of visit } & \multicolumn{2}{|c|}{ No. of visits } & \multicolumn{2}{|c|}{ Total payment } & \multicolumn{2}{|c|}{ Out of pocket cost } \\
\hline & (1) & $(2)$ & $(3)$ & (4) & (5) & (6) & (7) & (8) \\
\hline \multicolumn{9}{|l|}{ Bandwidth $=36$ months } \\
\hline Parametric (Linear) & $\begin{array}{c}-0.019 * * * \\
(0.005)\end{array}$ & $\begin{array}{c}-0.019 * * * \\
(0.005)\end{array}$ & $\begin{array}{c}-0.033^{* * *} \\
(0.012)\end{array}$ & $\begin{array}{c}-0.035^{* * *} \\
(0.012)\end{array}$ & $\begin{array}{l}-5.346 \\
(4.799)\end{array}$ & $\begin{array}{l}-5.431 \\
(4.864)\end{array}$ & $\begin{array}{l}-1.809^{*} \\
(1.058)\end{array}$ & $\begin{array}{l}-1.703 \\
(1.075)\end{array}$ \\
\hline Parametric (Quadratic) & $\begin{array}{c}-0.014^{* *} \\
(0.006)\end{array}$ & $\begin{array}{c}-0.016^{* *} \\
(0.006)\end{array}$ & $\begin{array}{c}-0.030^{*} \\
(0.017)\end{array}$ & $\begin{array}{c}-0.035^{* *} \\
(0.017)\end{array}$ & $\begin{array}{l}-7.667 \\
(7.145)\end{array}$ & $\begin{array}{l}-8.345 \\
(7.262)\end{array}$ & $\begin{array}{l}-1.099 \\
(1.591)\end{array}$ & $\begin{array}{l}-1.217 \\
(1.599)\end{array}$ \\
\hline Parametric (Cubic) & $\begin{array}{c}-0.036^{* * *} \\
(0.009)\end{array}$ & $\begin{array}{c}-0.033^{* * *} \\
(0.009)\end{array}$ & $\begin{array}{c}-0.038^{*} \\
(0.021)\end{array}$ & $\begin{array}{l}-0.031 \\
(0.022)\end{array}$ & $\begin{array}{c}-16.883^{*} \\
(10.054)\end{array}$ & $\begin{array}{l}-15.746 \\
(10.218)\end{array}$ & $\begin{array}{l}-0.232 \\
(1.874)\end{array}$ & $\begin{array}{l}-0.006 \\
(1.915)\end{array}$ \\
\hline Mean & 0.147 & 0.148 & 0.258 & 0.259 & 50.63 & 50.83 & 9.21 & 9.24 \\
\hline No. of obs. & 103409 & 102537 & 103409 & 102537 & 103409 & 102537 & 103409 & 102537 \\
\hline \multicolumn{9}{|l|}{ Bandwidth $=24$ months } \\
\hline Parametric (Linear) & $\begin{array}{c}-0.018^{* * *} \\
(0.005)\end{array}$ & $\begin{array}{c}-0.020^{* * *} \\
(0.005)\end{array}$ & $\begin{array}{c}-0.033^{* *} \\
(0.013)\end{array}$ & $\begin{array}{c}-0.037^{* * *} \\
(0.014)\end{array}$ & $\begin{array}{c}-9.698^{* *} \\
(4.573)\end{array}$ & $\begin{array}{c}-9.986 * * \\
(4.654)\end{array}$ & $\begin{array}{c}-1.130 \\
(1.371)\end{array}$ & $\begin{array}{l}-1.141 \\
(1.386)\end{array}$ \\
\hline Parametric (Quadratic) & $\begin{array}{c}-0.024^{* * *} \\
(0.007)\end{array}$ & $\begin{array}{c}-0.023^{* * *} \\
(0.007)\end{array}$ & $\begin{array}{l}-0.022 \\
(0.020)\end{array}$ & $\begin{array}{l}-0.019 \\
(0.021)\end{array}$ & $\begin{array}{l}-8.415 \\
(7.561)\end{array}$ & $\begin{array}{l}-7.804 \\
(7.757)\end{array}$ & $\begin{array}{c}0.530 \\
(1.836)\end{array}$ & $\begin{array}{c}0.683 \\
(1.861)\end{array}$ \\
\hline Parametric (Cubic) & $\begin{array}{c}-0.027^{* * *} \\
(0.008)\end{array}$ & $\begin{array}{c}-0.028^{* * *} \\
(0.008)\end{array}$ & $\begin{array}{c}-0.089 * * * \\
(0.026)\end{array}$ & $\begin{array}{c}-0.090^{* * *} \\
(0.027)\end{array}$ & $\begin{array}{l}-11.137 \\
(11.027)\end{array}$ & $\begin{array}{l}-11.743 \\
(11.390)\end{array}$ & $\begin{array}{c}-8.401^{* * *} \\
(2.131)\end{array}$ & $\begin{array}{c}-8.542^{* * *} \\
(2.159)\end{array}$ \\
\hline Mean & 0.145 & 0.146 & 0.256 & 0.257 & 48.34 & 48.59 & 8.99 & 9.034 \\
\hline No. of obs. & 69104 & 68453 & 69104 & 68453 & 69104 & 68453 & 69104 & 68453 \\
\hline \multicolumn{9}{|l|}{ Bandwidth $=12$ months } \\
\hline Parametric (Linear) & $\begin{array}{c}-0.022^{* * *} \\
(0.008)\end{array}$ & $\begin{array}{c}-0.022^{* * *} \\
(0.008)\end{array}$ & $\begin{array}{c}-0.051^{* * *} \\
(0.014)\end{array}$ & $\begin{array}{c}-0.052^{* * *} \\
(0.015)\end{array}$ & $\begin{array}{c}-12.596^{*} \\
(7.085)\end{array}$ & $\begin{array}{c}-12.646^{*} \\
(7.200)\end{array}$ & $\begin{array}{c}-3.104^{* *} \\
(1.195)\end{array}$ & $\begin{array}{c}-3.074^{* *} \\
(1.192)\end{array}$ \\
\hline Parametric (Quadratic) & $\begin{array}{c}-0.028^{* * *} \\
(0.010)\end{array}$ & $\begin{array}{c}-0.029 * * * \\
(0.010)\end{array}$ & $\begin{array}{c}-0.040^{* *} \\
(0.018)\end{array}$ & $\begin{array}{c}-0.041^{* *} \\
(0.019)\end{array}$ & $\begin{array}{c}-6.359 \\
(10.696)\end{array}$ & $\begin{array}{c}-6.814 \\
(10.886)\end{array}$ & $\begin{array}{l}-2.747 \\
(1.951)\end{array}$ & $\begin{array}{l}-2.829 \\
(1.964)\end{array}$ \\
\hline
\end{tabular}




\begin{tabular}{|c|c|c|c|c|c|c|c|c|}
\hline Parametric (Cubic) & $\begin{array}{l}-0.008 \\
(0.013)\end{array}$ & $\begin{array}{l}-0.011 \\
(0.013)\end{array}$ & $\begin{array}{c}0.009 \\
(0.028)\end{array}$ & $\begin{array}{c}0.004 \\
(0.028)\end{array}$ & $\begin{array}{c}-4.687 \\
(13.246)\end{array}$ & $\begin{array}{c}-5.491 \\
(13.386)\end{array}$ & $\begin{array}{c}-4.861^{*} \\
(2.687)\end{array}$ & $\begin{array}{c}-5.087^{*} \\
(2.615)\end{array}$ \\
\hline Mean & 0.140 & 0.141 & 0.236 & 0.237 & 45.21 & 45.47 & 8.08 & 8.13 \\
\hline No. of obs. & 35194 & 34881 & 35194 & 34881 & 35194 & 34881 & 35194 & 34881 \\
\hline Non-parametric (IK) & $\begin{array}{c}-0.022^{* * *} \\
(0.004) \\
{[20.894]}\end{array}$ & & $\begin{array}{c}-0.040^{* * *} \\
(0.011) \\
{[18.076]}\end{array}$ & & $\begin{array}{c}-8.925 \\
(5.519) \\
{[22.005]}\end{array}$ & & $\begin{array}{c}-2.241^{* *} \\
(1.051) \\
{[16.847}\end{array}$ & \\
\hline Controls & No & Yes & No & Yes & No & Yes & No & Yes \\
\hline
\end{tabular}

Notes: In all regressions, sample weights are used and standard errors are clustered by the forcing variable. Standard errors are reported in parentheses. Optimal Imbens-Kalyanaraman (IK) bandwidths are reported in brackets. The signs *,**, and *** denote statistical significance at 10,5 , and 1 percent. 
Table 5. Change in outpatient visits at age 26: RD estimates

\begin{tabular}{|c|c|c|c|c|c|c|c|c|}
\hline & \multicolumn{2}{|c|}{ Prob. of visit } & \multicolumn{2}{|c|}{ No. of visits } & \multicolumn{2}{|c|}{ Total payment } & \multicolumn{2}{|c|}{ Out of pocket cost } \\
\hline & (1) & $(2)$ & $(3)$ & (4) & (5) & (6) & (7) & (8) \\
\hline \multicolumn{9}{|l|}{ Bandwidth $=36$ months } \\
\hline \multirow[t]{2}{*}{ Parametric (Linear) } & -0.002 & -0.002 & -0.003 & -0.003 & -3.133 & -3.630 & 0.999 & 1.011 \\
\hline & $(0.002)$ & $(0.002)$ & $(0.003)$ & $(0.003)$ & $(5.577)$ & $(5.731)$ & $(0.780)$ & $(0.792)$ \\
\hline \multirow[t]{2}{*}{ Parametric (Quadratic) } & -0.001 & -0.001 & 0.000 & -0.000 & $10.587^{*}$ & $10.259^{*}$ & 0.263 & 0.273 \\
\hline & $(0.002)$ & $(0.002)$ & $(0.004)$ & $(0.004)$ & $(5.604)$ & $(5.646)$ & $(0.916)$ & $(0.928)$ \\
\hline \multirow[t]{2}{*}{ Parametric (Cubic) } & 0.000 & 0.000 & 0.005 & 0.005 & 12.846 & 13.093 & -1.164 & -1.159 \\
\hline & $(0.003)$ & $(0.003)$ & $(0.004)$ & $(0.004)$ & $(9.016)$ & $(9.068)$ & $(1.480)$ & $(1.494)$ \\
\hline Mean & 0.011 & 0.011 & 0.017 & 0.016 & 16.40 & 16.44 & 1.36 & 1.37 \\
\hline No. of obs. & 103409 & 102537 & 103409 & 102537 & 103409 & 102537 & 103409 & 102537 \\
\hline \multicolumn{9}{|l|}{ Bandwidth $=24$ months } \\
\hline \multirow[t]{2}{*}{ Parametric (Linear) } & -0.001 & -0.001 & 0.001 & 0.001 & 2.466 & 1.885 & 0.753 & 0.752 \\
\hline & $(0.002)$ & $(0.002)$ & $(0.003)$ & $(0.003)$ & $(5.627)$ & $(5.707)$ & $(0.834)$ & $(0.855)$ \\
\hline \multirow[t]{2}{*}{ Parametric (Quadratic) } & -0.001 & -0.001 & 0.000 & -0.000 & $16.512^{*}$ & $16.490^{*}$ & -0.835 & -0.839 \\
\hline & $(0.003)$ & $(0.003)$ & $(0.004)$ & $(0.004)$ & $(8.312)$ & $(8.361)$ & $(1.314)$ & $(1.323)$ \\
\hline \multirow[t]{2}{*}{ Parametric (Cubic) } & -0.003 & -0.003 & -0.002 & -0.002 & 0.939 & 1.342 & -1.564 & -1.586 \\
\hline & $(0.003)$ & $(0.003)$ & $(0.006)$ & $(0.006)$ & $(8.528)$ & $(8.660)$ & $(1.693)$ & $(1.717)$ \\
\hline Mean & 0.011 & 0.011 & 0.016 & 0.016 & 16.38 & 16.41 & 1.43 & 1.44 \\
\hline No. of obs. & 69104 & 68453 & 69104 & 68453 & 69104 & 68453 & 69104 & 68453 \\
\hline \multicolumn{9}{|l|}{ Bandwidth=12 months } \\
\hline \multirow[t]{2}{*}{ Parametric (Linear) } & -0.001 & -0.001 & 0.001 & 0.001 & 8.794 & 8.675 & -0.732 & -0.748 \\
\hline & $(0.002)$ & $(0.002)$ & $(0.003)$ & $(0.003)$ & $(6.266)$ & $(6.355)$ & $(1.482)$ & $(1.498)$ \\
\hline \multirow[t]{2}{*}{ Parametric (Quadratic) } & -0.003 & -0.003 & 0.005 & 0.005 & 7.508 & 7.612 & -1.134 & -1.156 \\
\hline & $(0.003)$ & $(0.003)$ & $(0.004)$ & $(0.004)$ & $(10.325)$ & $(10.434)$ & $(1.690)$ & $(1.694)$ \\
\hline
\end{tabular}




\begin{tabular}{lcccccccc} 
Parametric (Cubic) & -0.001 & -0.001 & -0.003 & -0.003 & $-26.666^{* *}$ & $-27.056^{* *}$ & -2.675 & -2.753 \\
& $(0.006)$ & $(0.006)$ & $(0.007)$ & $(0.007)$ & $(10.362)$ & $(10.421)$ & $(2.300)$ & $(2.275)$ \\
Mean & 0.010 & 0.010 & 0.013 & 0.013 & 12.34 & 12.41 & 1.41 & 1.41 \\
No. of obs. & 35194 & 34881 & 35194 & 34881 & 35194 & 34881 & 35194 & 34881 \\
\hline Non-parametric (IK) & -0.001 & & -0.001 & & $8.397^{*}$ & & -0.885 & $(1.220)$ \\
& $(0.002)$ & & $(0.003)$ & & $(5.099)$ & {$[11.959]$} & No \\
\hline Controls & {$[32.848]$} & & {$[19.342]$} & & {$[12.946]$} & Yes & Yes \\
\hline
\end{tabular}

Notes: In all regressions, sample weights are used and standard errors are clustered by the forcing variable. Standard errors are reported in parentheses. Optimal Imbens-Kalyanaraman (IK) bandwidths are reported in brackets. The signs * and ** denote statistical significance at 10 and 5 percent. 
Table 6. Change in dental visits at age 26: RD estimates

\begin{tabular}{|c|c|c|c|c|c|c|c|c|}
\hline & \multicolumn{2}{|c|}{ Prob. of visit } & \multicolumn{2}{|c|}{ No. of visits } & \multicolumn{2}{|c|}{ Total payment } & \multicolumn{2}{|c|}{ Out of pocket cost } \\
\hline & (1) & $(2)$ & $(3)$ & $(4)$ & $(5)$ & $(6)$ & $(7)$ & $(8)$ \\
\hline \multicolumn{9}{|l|}{ Bandwidth $=36$ months } \\
\hline Parametric (Linear) & $\begin{array}{c}-0.011^{* * *} \\
(0.003)\end{array}$ & $\begin{array}{c}-0.010^{* * *} \\
(0.003)\end{array}$ & $\begin{array}{c}-0.015^{* * *} \\
(0.004)\end{array}$ & $\begin{array}{c}-0.015^{* * *} \\
(0.004)\end{array}$ & $\begin{array}{l}-1.482 \\
(3.538)\end{array}$ & $\begin{array}{l}-1.241 \\
(3.624)\end{array}$ & $\begin{array}{l}-0.543 \\
(1.797)\end{array}$ & $\begin{array}{l}-0.565 \\
(1.825)\end{array}$ \\
\hline Parametric (Quadratic) & $\begin{array}{c}-0.011^{* *} \\
(0.005)\end{array}$ & $\begin{array}{c}-0.012^{* *} \\
(0.005)\end{array}$ & $\begin{array}{c}-0.017^{* * *} \\
(0.006)\end{array}$ & $\begin{array}{c}-0.018^{* * *} \\
(0.006)\end{array}$ & $\begin{array}{c}1.207 \\
(5.874)\end{array}$ & $\begin{array}{c}1.062 \\
(5.940)\end{array}$ & $\begin{array}{c}0.131 \\
(1.932)\end{array}$ & $\begin{array}{c}0.024 \\
(1.947)\end{array}$ \\
\hline Parametric (Cubic) & $\begin{array}{c}-0.011^{*} \\
(0.007)\end{array}$ & $\begin{array}{l}-0.011 \\
(0.007)\end{array}$ & $\begin{array}{c}-0.018^{* *} \\
(0.009)\end{array}$ & $\begin{array}{c}-0.018^{* *} \\
(0.009)\end{array}$ & $\begin{array}{l}-0.971 \\
(7.869)\end{array}$ & $\begin{array}{l}-0.954 \\
(7.931)\end{array}$ & $\begin{array}{l}-2.035 \\
(2.460)\end{array}$ & $\begin{array}{l}-2.030 \\
(2.479)\end{array}$ \\
\hline Mean & 0.038 & 0.038 & 0.043 & 0.044 & 13.21 & 13.27 & 5.55 & 5.58 \\
\hline No. of obs. & 103409 & 102537 & 103409 & 102537 & 103409 & 102537 & 103409 & 102537 \\
\hline \multicolumn{9}{|l|}{ Bandwidth $=24$ months } \\
\hline Parametric (Linear) & $\begin{array}{c}-0.010 * * \\
(0.004)\end{array}$ & $\begin{array}{c}-0.010 * * \\
(0.004)\end{array}$ & $\begin{array}{c}-0.014^{* * *} \\
(0.005)\end{array}$ & $\begin{array}{c}-0.014^{* * *} \\
(0.005)\end{array}$ & $\begin{array}{c}0.681 \\
(4.496)\end{array}$ & $\begin{array}{c}0.721 \\
(4.583)\end{array}$ & $\begin{array}{c}0.574 \\
(1.664)\end{array}$ & $\begin{array}{c}0.521 \\
(1.685)\end{array}$ \\
\hline Parametric (Quadratic) & $\begin{array}{c}-0.014^{* *} \\
(0.006)\end{array}$ & $\begin{array}{c}-0.014^{* *} \\
(0.006)\end{array}$ & $\begin{array}{c}-0.021^{* * *} \\
(0.007)\end{array}$ & $\begin{array}{c}-0.021^{* * *} \\
(0.008)\end{array}$ & $\begin{array}{l}-2.006 \\
(7.314)\end{array}$ & $\begin{array}{l}-2.016 \\
(7.382)\end{array}$ & $\begin{array}{l}-2.940 \\
(2.166)\end{array}$ & $\begin{array}{l}-2.974 \\
(2.193)\end{array}$ \\
\hline Parametric (Cubic) & $\begin{array}{c}-0.013 \\
(0.008)\end{array}$ & $\begin{array}{c}-0.013 \\
(0.008)\end{array}$ & $\begin{array}{c}-0.019^{* *} \\
(0.009)\end{array}$ & $\begin{array}{c}-0.019^{*} \\
(0.010)\end{array}$ & $\begin{array}{c}2.036 \\
(9.260)\end{array}$ & $\begin{array}{c}2.026 \\
(9.344)\end{array}$ & $\begin{array}{l}-1.631 \\
(2.738)\end{array}$ & $\begin{array}{l}-1.619 \\
(2.778)\end{array}$ \\
\hline Mean & 0.038 & 0.038 & 0.043 & 0.043 & 12.90 & 12.98 & 5.47 & 5.50 \\
\hline No. of obs. & 69104 & 68453 & 69104 & 68453 & 69104 & 68453 & 69104 & 68453 \\
\hline Bandwidth=12 months & & & & & & & & \\
\hline Parametric (Linear) & $\begin{array}{c}-0.012^{* *} \\
(0.006)\end{array}$ & $\begin{array}{c}-0.011^{*} \\
(0.006)\end{array}$ & $\begin{array}{c}-0.019^{* * *} \\
(0.007)\end{array}$ & $\begin{array}{c}-0.019^{* *} \\
(0.007)\end{array}$ & $\begin{array}{l}-2.217 \\
(7.280)\end{array}$ & $\begin{array}{l}-2.173 \\
(7.367)\end{array}$ & $\begin{array}{l}-2.968 \\
(2.354)\end{array}$ & $\begin{array}{l}-2.981 \\
(2.403)\end{array}$ \\
\hline Parametric (Quadratic) & $\begin{array}{c}-0.016^{*} \\
(0.009)\end{array}$ & $\begin{array}{c}-0.016^{*} \\
(0.009)\end{array}$ & $\begin{array}{c}-0.020^{*} \\
(0.011)\end{array}$ & $\begin{array}{c}-0.020^{*} \\
(0.011)\end{array}$ & $\begin{array}{c}7.546 \\
(10.796)\end{array}$ & $\begin{array}{c}7.396 \\
(10.879)\end{array}$ & $\begin{array}{c}2.911 \\
(3.927)\end{array}$ & $\begin{array}{c}2.908 \\
(3.981)\end{array}$ \\
\hline
\end{tabular}




\begin{tabular}{lcccccccc} 
Parametric (Cubic) & $-0.020^{*}$ & $-0.021^{* *}$ & $-0.029^{* *}$ & $-0.030^{* *}$ & -5.785 & -6.229 & -5.424 & -5.560 \\
& $(0.010)$ & $(0.010)$ & $(0.011)$ & $(0.011)$ & $(10.361)$ & $(10.515)$ & $(3.565)$ & $(3.614)$ \\
Mean & 0.039 & 0.039 & 0.044 & 0.044 & 13.76 & 13.84 & 5.47 & 5.50 \\
No. of obs. & 35194 & 34881 & 35194 & 34881 & 35194 & 34881 & 35194 & 34881 \\
\hline Non-parametric (IK) & $-0.012^{* *}$ & & $-0.019^{* * *}$ & & -0.179 & & -1.161 & $(1.470)$ \\
& $(0.005)$ & & $(0.007)$ & & $(4.384)$ & {$[33.539]$} & & {$[22.013]$} \\
\hline Controls & {$[21.322]$} & & {$[14.876]$} & & No & Yes & No & Yes \\
\hline
\end{tabular}

Notes: In all regressions, sample weights are used and standard errors are clustered by the forcing variable. Standard errors are reported in parentheses. Optimal Imbens-Kalyanaraman (IK) bandwidths are reported in brackets. The signs *,**, and *** denote statistical significance at 10,5 , and 1 percent. 
Table 7. Change in emergency department visits at age 26: RD estimates

\begin{tabular}{|c|c|c|c|c|c|c|c|c|}
\hline & \multicolumn{2}{|c|}{ Prob. of visit } & \multicolumn{2}{|c|}{ No. of visits } & \multicolumn{2}{|c|}{ Total payment } & \multicolumn{2}{|c|}{ Out of pocket cost } \\
\hline & (1) & $(2)$ & $(3)$ & (4) & (5) & (6) & (7) & (8) \\
\hline \multicolumn{9}{|l|}{ Bandwidth $=36$ months } \\
\hline Parametric (Linear) & $\begin{array}{c}-0.002 \\
(0.002)\end{array}$ & $\begin{array}{c}-0.002 \\
(0.002)\end{array}$ & $\begin{array}{c}-0.001 \\
(0.002)\end{array}$ & $\begin{array}{l}-0.002 \\
(0.002)\end{array}$ & $\begin{array}{l}-6.925^{*} \\
(3.548)\end{array}$ & $\begin{array}{c}-7.283^{* *} \\
(3.529)\end{array}$ & $\begin{array}{c}-2.081^{* *} \\
(1.025)\end{array}$ & $\begin{array}{c}-2.077^{* *} \\
(1.029)\end{array}$ \\
\hline Parametric (Quadratic) & $\begin{array}{l}-0.003 \\
(0.002)\end{array}$ & $\begin{array}{l}-0.003 \\
(0.002)\end{array}$ & $\begin{array}{l}-0.002 \\
(0.003)\end{array}$ & $\begin{array}{l}-0.003 \\
(0.003)\end{array}$ & $\begin{array}{l}-4.361 \\
(3.830)\end{array}$ & $\begin{array}{l}-4.366 \\
(3.862)\end{array}$ & $\begin{array}{l}-1.511 \\
(1.481)\end{array}$ & $\begin{array}{c}-1.621 \\
(1.501)\end{array}$ \\
\hline Parametric (Cubic) & $\begin{array}{l}-0.003 \\
(0.003)\end{array}$ & $\begin{array}{c}-0.002 \\
(0.003)\end{array}$ & $\begin{array}{l}-0.002 \\
(0.003)\end{array}$ & $\begin{array}{l}-0.001 \\
(0.003)\end{array}$ & $\begin{array}{l}-1.121 \\
(4.800)\end{array}$ & $\begin{array}{l}-1.017 \\
(4.811)\end{array}$ & $\begin{array}{c}0.558 \\
(1.953)\end{array}$ & $\begin{array}{c}0.640 \\
(1.978)\end{array}$ \\
\hline Mean & 0.015 & 0.015 & 0.017 & 0.017 & 15.55 & 15.54 & 2.74 & 2.74 \\
\hline No. of obs. & 103409 & 102537 & 103409 & 102537 & 103409 & 102537 & 103409 & 102537 \\
\hline \multicolumn{9}{|l|}{ Bandwidth $=24$ months } \\
\hline Parametric (Linear) & $\begin{array}{l}-0.002 \\
(0.002)\end{array}$ & $\begin{array}{l}-0.003 \\
(0.002)\end{array}$ & $\begin{array}{c}-0.001 \\
(0.002)\end{array}$ & $\begin{array}{l}-0.002 \\
(0.002)\end{array}$ & $\begin{array}{l}-4.078 \\
(3.639)\end{array}$ & $\begin{array}{l}-4.082 \\
(3.650)\end{array}$ & $\begin{array}{l}-1.714 \\
(1.438)\end{array}$ & $\begin{array}{l}-1.765 \\
(1.465)\end{array}$ \\
\hline Parametric (Quadratic) & $\begin{array}{c}-0.002 \\
(0.002)\end{array}$ & $\begin{array}{c}-0.002 \\
(0.002)\end{array}$ & $\begin{array}{c}-0.002 \\
(0.003)\end{array}$ & $\begin{array}{c}-0.002 \\
(0.003)\end{array}$ & $\begin{array}{l}-2.353 \\
(3.400)\end{array}$ & $\begin{array}{l}-2.656 \\
(3.465)\end{array}$ & $\begin{array}{c}0.267 \\
(2.059)\end{array}$ & $\begin{array}{c}0.280 \\
(2.076)\end{array}$ \\
\hline Parametric (Cubic) & $\begin{array}{c}-0.008^{* *} \\
(0.003)\end{array}$ & $\begin{array}{c}-0.008^{* *} \\
(0.003)\end{array}$ & $\begin{array}{c}-0.006 \\
(0.005)\end{array}$ & $\begin{array}{c}-0.006 \\
(0.005)\end{array}$ & $\begin{array}{c}-14.103^{*} \\
(7.407)\end{array}$ & $\begin{array}{c}-13.939^{*} \\
(7.434)\end{array}$ & $\begin{array}{l}-2.871 \\
(2.120)\end{array}$ & $\begin{array}{l}-2.903 \\
(2.133)\end{array}$ \\
\hline Mean & 0.015 & 0.015 & 0.016 & 0.016 & 14.04 & 14.04 & 2.37 & 2.38 \\
\hline No. of obs. & 69104 & 68453 & 69104 & 68453 & 69104 & 68453 & 69104 & 68453 \\
\hline \multicolumn{9}{|l|}{ Bandwidth=12 months } \\
\hline Parametric (Linear) & $\begin{array}{c}-0.006^{* *} \\
(0.002)\end{array}$ & $\begin{array}{c}-0.006^{* *} \\
(0.002)\end{array}$ & $\begin{array}{c}-0.005^{*} \\
(0.003)\end{array}$ & $\begin{array}{c}-0.005^{*} \\
(0.003)\end{array}$ & $\begin{array}{c}-7.187^{* *} \\
(3.094)\end{array}$ & $\begin{array}{c}-7.305^{* *} \\
(3.098)\end{array}$ & $\begin{array}{l}-2.136 \\
(1.460)\end{array}$ & $\begin{array}{c}-2.141 \\
(1.480)\end{array}$ \\
\hline Parametric (Quadratic) & $\begin{array}{c}-0.004 \\
(0.003)\end{array}$ & $\begin{array}{l}-0.003 \\
(0.003)\end{array}$ & $\begin{array}{l}-0.002 \\
(0.004)\end{array}$ & $\begin{array}{l}-0.001 \\
(0.004)\end{array}$ & $\begin{array}{c}-7.747 \\
(7.268)\end{array}$ & $\begin{array}{l}-7.850 \\
(7.253)\end{array}$ & $\begin{array}{c}0.409 \\
(1.893)\end{array}$ & $\begin{array}{c}0.415 \\
(1.902)\end{array}$ \\
\hline
\end{tabular}




\begin{tabular}{|c|c|c|c|c|c|c|c|c|}
\hline Parametric (Cubic) & $\begin{array}{c}0.002 \\
(0.005)\end{array}$ & $\begin{array}{c}0.002 \\
(0.005)\end{array}$ & $\begin{array}{l}0.011^{*} \\
(0.005)\end{array}$ & $\begin{array}{c}0.011^{* *} \\
(0.005)\end{array}$ & $\begin{array}{c}10.188 \\
(10.734)\end{array}$ & $\begin{array}{c}10.265 \\
(10.907)\end{array}$ & $\begin{array}{c}0.317 \\
(2.752)\end{array}$ & $\begin{array}{c}0.354 \\
(2.779)\end{array}$ \\
\hline Mean & 0.015 & 0.015 & 0.017 & 0.017 & 13.47 & 13.54 & 1.81 & 1.82 \\
\hline No. of obs. & 35194 & 34881 & 35194 & 34881 & 35194 & 34881 & 35194 & 34881 \\
\hline Non-parametric (IK) & $\begin{array}{c}-0.002 \\
(0.002) \\
{[27.051]} \\
\end{array}$ & & $\begin{array}{l}-0.002 \\
(0.002) \\
{[25.192]} \\
\end{array}$ & & $\begin{array}{c}-4.591 * * \\
(2.317) \\
{[19.431]}\end{array}$ & & $\begin{array}{l}-1.038 \\
(1.118) \\
{[25.164]} \\
\end{array}$ & \\
\hline Controls & No & Yes & No & Yes & No & Yes & No & Yes \\
\hline
\end{tabular}

Notes: In all regressions, sample weights are used and standard errors are clustered by the forcing variable. Standard errors are reported in parentheses. Optimal Imbens-Kalyanaraman (IK) bandwidths are reported in brackets. The signs * and ** denote statistical significance at 10 and 5 percent. 
Table 8. Change in health insurance coverage at age 26: Alternative samples

\begin{tabular}{|c|c|c|c|c|}
\hline & Any insurance & $\begin{array}{l}\text { Private } \\
\text { insurance }\end{array}$ & $\begin{array}{l}\text { Public } \\
\text { insurance }\end{array}$ & $\begin{array}{c}\text { Holder } \\
\text { outside of RU }\end{array}$ \\
\hline Female & $\begin{array}{c}-0.031^{* * *} \\
(0.008)\end{array}$ & $\begin{array}{l}-0.016 \\
(0.010)\end{array}$ & $\begin{array}{c}-0.014^{* * *} \\
(0.004)\end{array}$ & $\begin{array}{c}-0.038^{* * *} \\
(0.004)\end{array}$ \\
\hline No. of obs. & 36600 & 36600 & 36600 & 36600 \\
\hline Male & $\begin{array}{c}-0.033^{* * *} \\
(0.009)\end{array}$ & $\begin{array}{c}-0.029^{* * *} \\
(0.006)\end{array}$ & $\begin{array}{c}0.001 \\
(0.006)\end{array}$ & $\begin{array}{c}-0.032^{* * *} \\
(0.002)\end{array}$ \\
\hline No. of obs. & 31565 & 31565 & 31565 & 31565 \\
\hline White & $\begin{array}{c}-0.022^{* *} \\
(0.010)\end{array}$ & $\begin{array}{c}-0.017^{* *} \\
(0.008)\end{array}$ & $\begin{array}{l}-0.002 \\
(0.004)\end{array}$ & $\begin{array}{c}-0.039^{* * *} \\
(0.003)\end{array}$ \\
\hline No. of obs. & 45742 & 45742 & 45742 & 45742 \\
\hline Black & $\begin{array}{c}-0.051^{* * *} \\
(0.011)\end{array}$ & $\begin{array}{c}-0.018^{* * *} \\
(0.007)\end{array}$ & $\begin{array}{c}-0.046^{* * *} \\
(0.013)\end{array}$ & $\begin{array}{l}-0.005 \\
(0.005)\end{array}$ \\
\hline No. of obs. & 14051 & 14051 & 14051 & 14051 \\
\hline Employed & $\begin{array}{c}-0.036^{* * *} \\
(0.007)\end{array}$ & $\begin{array}{c}-0.027^{* * *} \\
(0.005)\end{array}$ & $\begin{array}{l}-0.005 \\
(0.003)\end{array}$ & $\begin{array}{c}-0.040^{* * *} \\
(0.003)\end{array}$ \\
\hline No. of obs. & 51360 & 51360 & 51360 & 51360 \\
\hline Unemployed & $\begin{array}{c}-0.043^{* *} \\
(0.016)\end{array}$ & $\begin{array}{c}-0.027^{*} \\
(0.014)\end{array}$ & $\begin{array}{c}-0.017^{*} \\
(0.009)\end{array}$ & $\begin{array}{l}-0.006 \\
(0.007)\end{array}$ \\
\hline No. of obs. & 16362 & 16362 & 16362 & 16362 \\
\hline Married & $\begin{array}{c}0.001 \\
(0.010)\end{array}$ & $\begin{array}{c}0.036^{* * *} \\
(0.011)\end{array}$ & $\begin{array}{c}-0.025^{* * *} \\
(0.005)\end{array}$ & $\begin{array}{c}0.002 \\
(0.006)\end{array}$ \\
\hline No. of obs. & 20210 & 20210 & 20210 & 20210 \\
\hline Poor/near poor & $\begin{array}{l}-0.026 \\
(0.016)\end{array}$ & $\begin{array}{c}-0.041^{* * *} \\
(0.010)\end{array}$ & $\begin{array}{c}0.014 \\
(0.009)\end{array}$ & $\begin{array}{c}-0.036^{* * *} \\
(0.005)\end{array}$ \\
\hline No. of obs. & 19837 & 19837 & 19837 & 19837 \\
\hline Low income & $\begin{array}{c}-0.075^{* * *} \\
(0.013)\end{array}$ & $\begin{array}{c}-0.035^{* * *} \\
(0.013)\end{array}$ & $\begin{array}{c}-0.031^{* * *} \\
(0.010)\end{array}$ & $\begin{array}{l}-0.001 \\
(0.012)\end{array}$ \\
\hline No. of obs. & 12924 & 12924 & 12924 & 12924 \\
\hline Middle/high income & $\begin{array}{c}-0.025^{* * *} \\
(0.009)\end{array}$ & $\begin{array}{c}-0.017^{* *} \\
(0.008)\end{array}$ & $\begin{array}{c}-0.004^{*} \\
(0.002)\end{array}$ & $\begin{array}{c}-0.041^{* * *} \\
(0.003)\end{array}$ \\
\hline No. of obs. & 35404 & 35404 & 35404 & 35404 \\
\hline
\end{tabular}

Notes: Estimates from parametric RD models with an age bandwidth of two years are reported. All models contain a quadratic polynomial of the forcing variable that is also fully interacted with the treatment variable. All models contain a set of control variables as discussed in the text. In all regressions, sample weights are used and standard errors are clustered by the forcing variable. Standard errors are reported in parentheses. The signs $*, * *, * * *$ denote statistical significance at 10,5 , and 1 percent. 
Table 9. Change in the probability of using different types of health care at age 26: Alternative samples

\begin{tabular}{|c|c|c|c|c|}
\hline & Office & $\begin{array}{l}\text { Emergency } \\
\text { department }\end{array}$ & Outpatient & Dentist \\
\hline \multirow[t]{2}{*}{ Female } & -0.020 & 0.000 & -0.000 & -0.011 \\
\hline & $(0.016)$ & $(0.003)$ & $(0.004)$ & $(0.011)$ \\
\hline No. of obs. & 36768 & 36768 & 36768 & 36768 \\
\hline \multirow[t]{2}{*}{ Male } & $-0.024^{* *}$ & -0.005 & -0.001 & $-0.016^{*}$ \\
\hline & $(0.010)$ & $(0.004)$ & $(0.004)$ & $(0.008)$ \\
\hline No. of obs. & 31685 & 31685 & 31685 & 31685 \\
\hline \multirow[t]{2}{*}{ White } & $-0.029 * * *$ & -0.004 & 0.002 & $-0.020^{* *}$ \\
\hline & $(0.009)$ & $(0.003)$ & $(0.003)$ & $(0.008)$ \\
\hline No. of obs. & 45883 & 45883 & 45883 & 45883 \\
\hline \multirow[t]{2}{*}{ Black } & -0.004 & 0.006 & -0.002 & $0.019^{* *}$ \\
\hline & $(0.014)$ & $(0.006)$ & $(0.005)$ & $(0.008)$ \\
\hline No. of obs. & 14102 & 14102 & 14102 & 14102 \\
\hline \multirow[t]{2}{*}{ Employed } & $-0.023^{* * *}$ & -0.003 & 0.001 & $-0.015^{* *}$ \\
\hline & $(0.008)$ & $(0.003)$ & $(0.003)$ & $(0.007)$ \\
\hline No. of obs. & 51386 & 51386 & 51386 & 51386 \\
\hline \multirow[t]{2}{*}{ Unemployed } & -0.024 & -0.000 & -0.006 & -0.009 \\
\hline & $(0.018)$ & $(0.006)$ & $(0.004)$ & $(0.009)$ \\
\hline No. of obs. & 16624 & 16624 & 16624 & 16624 \\
\hline \multirow[t]{2}{*}{ Married } & $-0.045^{* * *}$ & $-0.008^{* *}$ & -0.004 & $-0.016^{* *}$ \\
\hline & $(0.014)$ & $(0.004)$ & $(0.006)$ & $(0.008)$ \\
\hline No. of obs. & 20375 & 20375 & 20375 & 20375 \\
\hline \multirow[t]{2}{*}{ Poor/near poor } & $-0.037^{* *}$ & -0.005 & -0.006 & $-0.015^{*}$ \\
\hline & $(0.015)$ & $(0.009)$ & $(0.004)$ & $(0.009)$ \\
\hline No. of obs. & 19918 & 19918 & 19918 & 19918 \\
\hline \multirow[t]{2}{*}{ Low income } & -0.016 & -0.007 & -0.005 & $-0.023^{*}$ \\
\hline & $(0.020)$ & $(0.009)$ & $(0.007)$ & $(0.012)$ \\
\hline No. of obs. & 12977 & 12977 & 12977 & 12977 \\
\hline \multirow[t]{2}{*}{ Middle/high income } & $-0.020^{*}$ & 0.000 & 0.002 & -0.011 \\
\hline & $(0.012)$ & $(0.003)$ & $(0.004)$ & $(0.009)$ \\
\hline No. of obs. & 35558 & 35558 & 35558 & 35558 \\
\hline
\end{tabular}

Notes: Estimates from parametric RD models with an age bandwidth of two years are reported. All models contain a quadratic polynomial of the forcing variable that is also fully interacted with the treatment variable. All models contain a set of control variables as discussed in the text. In all regressions, sample weights are used and standard errors are clustered by the forcing variable. Standard errors are reported in parentheses. The signs $*, * *, * * *$ denote statistical significance at 10,5 , and 1 percent. 
Table 10. Change in the number of visits for different types of health care use at age 26: Alternative samples

\begin{tabular}{|c|c|c|c|c|}
\hline & Office & $\begin{array}{l}\text { Emergency } \\
\text { department }\end{array}$ & Outpatient & Dentist \\
\hline \multirow[t]{2}{*}{ Female } & 0.020 & 0.001 & -0.001 & -0.020 \\
\hline & $(0.031)$ & $(0.004)$ & $(0.007)$ & $(0.013)$ \\
\hline No. of obs. & 36768 & 36768 & 36768 & 36768 \\
\hline \multirow[t]{2}{*}{ Male } & $-0.056^{*}$ & -0.004 & 0.001 & $-0.022^{* *}$ \\
\hline & $(0.029)$ & $(0.004)$ & $(0.005)$ & $(0.009)$ \\
\hline No. of obs. & 31685 & 31685 & 31685 & 31685 \\
\hline \multirow[t]{2}{*}{ White } & -0.024 & -0.004 & 0.002 & $-0.027^{* *}$ \\
\hline & $(0.026)$ & $(0.004)$ & $(0.006)$ & $(0.010)$ \\
\hline No. of obs. & 45883 & 45883 & 45883 & 45883 \\
\hline \multirow[t]{2}{*}{ Black } & 0.019 & $0.014^{* *}$ & -0.004 & 0.017 \\
\hline & $(0.019)$ & $(0.007)$ & $(0.007)$ & $(0.010)$ \\
\hline No. of obs. & 14102 & 14102 & 14102 & 14102 \\
\hline \multirow[t]{2}{*}{ Employed } & -0.024 & -0.003 & 0.006 & $-0.024^{* * *}$ \\
\hline & $(0.024)$ & $(0.003)$ & $(0.004)$ & $(0.008)$ \\
\hline No. of obs. & 51386 & 51386 & 51386 & 51386 \\
\hline \multirow[t]{2}{*}{ Unemployed } & -0.002 & 0.003 & $-0.024^{*}$ & -0.009 \\
\hline & $(0.059)$ & $(0.007)$ & $(0.013)$ & $(0.014)$ \\
\hline No. of obs. & 16624 & 16624 & 16624 & 16624 \\
\hline \multirow[t]{2}{*}{ Married } & $-0.091^{* * *}$ & $-0.008^{*}$ & -0.005 & $-0.021^{* *}$ \\
\hline & $(0.029)$ & $(0.004)$ & $(0.008)$ & $(0.010)$ \\
\hline No. of obs. & 20375 & 20375 & 20375 & 20375 \\
\hline \multirow[t]{2}{*}{ Poor/near poor } & -0.066 & -0.004 & -0.009 & $-0.027^{* *}$ \\
\hline & $(0.051)$ & $(0.010)$ & $(0.005)$ & $(0.010)$ \\
\hline No. of obs. & 19918 & 19918 & 19918 & 19918 \\
\hline \multirow[t]{2}{*}{ Low income } & -0.060 & -0.006 & -0.005 & $-0.025^{*}$ \\
\hline & $(0.053)$ & $(0.010)$ & $(0.012)$ & $(0.014)$ \\
\hline No. of obs. & 12977 & 12977 & 12977 & 12977 \\
\hline \multirow[t]{2}{*}{ Middle/high income } & 0.005 & 0.001 & 0.004 & $-0.018^{*}$ \\
\hline & $(0.035)$ & $(0.003)$ & $(0.006)$ & $(0.011)$ \\
\hline No. of obs. & 35558 & 35558 & 35558 & 35558 \\
\hline
\end{tabular}

Notes: Estimates from parametric RD models with an age bandwidth of two years are reported. All models contain a quadratic polynomial of the forcing variable that is also fully interacted with the treatment variable. All models contain a set of control variables as discussed in the text. In all regressions, sample weights are used and standard errors are clustered by the forcing variable. Standard errors are reported in parentheses. The signs *,**, *** denote statistical significance at 10,5 , and 1 percent. 
Table 11. Change in total health care spending for different types of health care use at age 26: Conditional effect for alternative samples

\begin{tabular}{|c|c|c|c|c|}
\hline & Office & $\begin{array}{l}\text { Emergency } \\
\text { department }\end{array}$ & Outpatient & Dentist \\
\hline Full sample & $\begin{array}{c}-4.389 \\
(60.021)\end{array}$ & $\begin{array}{c}124.145 \\
(224.745)\end{array}$ & $\begin{array}{c}1378.092^{*} \\
(795.910)\end{array}$ & $\begin{array}{c}88.320 \\
(215.109)\end{array}$ \\
\hline No. of obs. & 8303 & 1034 & 616 & 2137 \\
\hline Female & $\begin{array}{c}76.059 \\
(46.716)\end{array}$ & $\begin{array}{c}215.536 \\
(329.759)\end{array}$ & $\begin{array}{c}1481.420^{*} \\
(857.024)\end{array}$ & $\begin{array}{c}256.968 \\
(291.821)\end{array}$ \\
\hline No. of obs. & 6291 & 708 & 437 & 1372 \\
\hline Male & $\begin{array}{l}-212.792 \\
(238.355)\end{array}$ & $\begin{array}{c}307.302 \\
(386.313)\end{array}$ & $\begin{array}{c}132.236 \\
(1317.756)\end{array}$ & $\begin{array}{l}-159.020 \\
(214.081)\end{array}$ \\
\hline No. of obs. & 2012 & 326 & 179 & 765 \\
\hline White & $\begin{array}{l}-26.787 \\
(76.292)\end{array}$ & $\begin{array}{c}391.716 \\
(319.558)\end{array}$ & $\begin{array}{c}983.042 \\
(872.638)\end{array}$ & $\begin{array}{c}37.313 \\
(261.119)\end{array}$ \\
\hline No. of obs. & 5991 & 679 & 461 & 1498 \\
\hline Black & $\begin{array}{c}185.228^{* * *} \\
(44.680)\end{array}$ & $\begin{array}{l}-781.706 \\
(520.908)\end{array}$ & $\begin{array}{c}4507.868 \\
(2936.194)\end{array}$ & $\begin{array}{c}160.685 \\
(190.332)\end{array}$ \\
\hline No. of obs. & 1419 & 287 & 92 & 361 \\
\hline Employed & $\begin{array}{l}-80.417 \\
(78.967)\end{array}$ & $\begin{array}{l}-124.094 \\
(355.470)\end{array}$ & $\begin{array}{l}1274.563 \\
(858.381)\end{array}$ & $\begin{array}{c}32.460 \\
(219.665)\end{array}$ \\
\hline No. of obs. & 5902 & 708 & 442 & 1757 \\
\hline Unemployed & $\begin{array}{c}187.524^{* *} \\
(78.197)\end{array}$ & $\begin{array}{c}414.813 \\
(433.664)\end{array}$ & $\begin{array}{c}2654.711 \\
(1786.473)\end{array}$ & $\begin{array}{c}414.185 \\
(288.632)\end{array}$ \\
\hline No. of obs. & 2390 & 325 & 174 & 376 \\
\hline Married & $\begin{array}{c}35.866 \\
(67.173)\end{array}$ & $\begin{array}{c}136.059 \\
(493.998)\end{array}$ & $\begin{array}{c}585.096 \\
(1150.785)\end{array}$ & $\begin{array}{c}521.581 \\
(498.097)\end{array}$ \\
\hline No. of obs. & 3138 & 285 & 208 & 771 \\
\hline Poor/near poor & $\begin{array}{l}100.903 \\
(63.593)\end{array}$ & $\begin{array}{l}465.664^{* *} \\
(221.730)\end{array}$ & $\begin{array}{c}1214.204 \\
(1073.384)\end{array}$ & $\begin{array}{c}-67.416 \\
(253.171)\end{array}$ \\
\hline No. of obs. & 2539 & 485 & 179 & 421 \\
\hline Low income & $\begin{array}{c}84.540 \\
(83.296)\end{array}$ & $\begin{array}{c}193.609 \\
(647.902)\end{array}$ & $\begin{array}{c}745.037 \\
(1706.486)\end{array}$ & $\begin{array}{c}7.146 \\
(172.192)\end{array}$ \\
\hline No. of obs. & 1377 & 211 & 109 & 319 \\
\hline Middle/high income & $\begin{array}{l}-71.827 \\
(94.819)\end{array}$ & $\begin{array}{c}-696.066 \\
(682.080)\end{array}$ & $\begin{array}{c}829.268 \\
(1251.482)\end{array}$ & $\begin{array}{c}102.219 \\
(281.448)\end{array}$ \\
\hline No. of obs. & 4387 & 338 & 328 & 1397 \\
\hline
\end{tabular}

Notes: Sample is restricted to those who used a particular health care service at least once at a given month. Estimates from parametric RD models with an age bandwidth of two years are reported. All models contain a quadratic polynomial of the forcing variable that is also fully interacted with the treatment variable. All models contain a set of control variables as discussed in the text. In all regressions, sample weights are used and standard errors are clustered by the forcing variable. Standard errors are reported in parentheses. The signs *, **, *** denote statistical significance at 10,5 , and 1 percent. 
Table 12. Change in out-of-pocket costs for different types of health care use at age 26: Conditional effect for alternative samples

\begin{tabular}{|c|c|c|c|c|}
\hline & Office & $\begin{array}{l}\text { Emergency } \\
\text { room }\end{array}$ & Outpatient & Dentist \\
\hline \multirow[t]{2}{*}{ Full sample } & 17.132 & 72.785 & -42.687 & -44.327 \\
\hline & $(13.452)$ & (126.104) & $(144.225)$ & $(62.181)$ \\
\hline No. of obs. & 8303 & 1034 & 616 & 2137 \\
\hline \multirow[t]{2}{*}{ Female } & 25.363 & 0.511 & 24.507 & -66.684 \\
\hline & $(15.191)$ & $(100.055)$ & $(120.986)$ & $(79.931)$ \\
\hline No. of obs. & 6291 & 708 & 437 & 1372 \\
\hline \multirow[t]{2}{*}{ Male } & -11.082 & 131.392 & -333.507 & 30.468 \\
\hline & $(28.347)$ & $(246.003)$ & $(351.013)$ & $(87.158)$ \\
\hline No. of obs. & 2012 & 326 & 179 & 765 \\
\hline \multirow[t]{2}{*}{ White } & 12.824 & -23.932 & -225.817 & -93.606 \\
\hline & $(16.733)$ & (118.586) & $(166.538)$ & $(77.646)$ \\
\hline No. of obs. & 5991 & 679 & 461 & 1498 \\
\hline \multirow{2}{*}{ Black } & 14.766 & 137.885 & $757.680^{* * *}$ & 95.071 \\
\hline & $(12.450)$ & $(174.145)$ & $(180.712)$ & $(69.539)$ \\
\hline No. of obs. & 1419 & 287 & 92 & 361 \\
\hline \multirow{2}{*}{ Employed } & 6.901 & -8.556 & -8.609 & -82.088 \\
\hline & $(18.232)$ & $(142.300)$ & $(172.318)$ & $(73.989)$ \\
\hline No. of obs. & 5902 & 708 & 442 & 1757 \\
\hline \multirow[t]{2}{*}{ Unemployed } & 56.290 & $283.239^{*}$ & -20.774 & 139.768 \\
\hline & $(38.400)$ & $(166.556)$ & $(213.906)$ & $(124.706)$ \\
\hline No. of obs. & 2390 & 325 & 174 & 376 \\
\hline \multirow[t]{2}{*}{ Married } & 32.235 & 77.430 & -359.841 & 44.063 \\
\hline & $(33.506)$ & $(258.153)$ & $(287.861)$ & $(107.709)$ \\
\hline No. of obs. & 3138 & 285 & 208 & 771 \\
\hline \multirow[t]{2}{*}{ Poor/near poor } & -0.637 & 76.899 & -0.743 & 53.383 \\
\hline & $(19.271)$ & $(196.111)$ & $(26.059)$ & $(72.660)$ \\
\hline No. of obs. & 2539 & 485 & 179 & 421 \\
\hline \multirow[t]{2}{*}{ Low income } & -40.225 & 101.035 & -624.855 & 193.166 \\
\hline & $(25.310)$ & $(237.428)$ & $(1133.151)$ & $(116.229)$ \\
\hline No. of obs. & 1377 & 211 & 109 & 319 \\
\hline \multirow[t]{2}{*}{ Middle/high income } & 34.943 & -41.771 & -209.972 & -97.532 \\
\hline & $(23.101)$ & $(187.146)$ & $(217.883)$ & $(88.043)$ \\
\hline No. of obs. & 4387 & 338 & 328 & 1397 \\
\hline
\end{tabular}

Notes: Sample is restricted to those who used a particular health care service at least once at a given month. Estimates from parametric RD models with an age bandwidth of two years are reported. All models contain a quadratic polynomial of the forcing variable that is also fully interacted with the treatment variable. All models contain a set of control variables as discussed in the text. In all regressions, sample weights are used and standard errors are clustered by the forcing variable. Standard errors are reported in parentheses. The signs ${ }^{*}$ and $* * *$ denote statistical significance at 10 and 1 percent. 
Table 13. The effect of health insurance coverage on the probability of using different types of health care: IV estimates

\begin{tabular}{|c|c|c|c|c|}
\hline & Office & $\begin{array}{l}\text { Emergency } \\
\text { department }\end{array}$ & Outpatient & Dentist \\
\hline \multirow[t]{2}{*}{ Full sample } & $0.735^{* *}$ & 0.070 & 0.017 & $0.429 * * *$ \\
\hline & $(0.324)$ & $(0.066)$ & $(0.087)$ & $(0.157)$ \\
\hline No. of obs. & 68165 & 68165 & 68165 & 68165 \\
\hline \multirow[t]{2}{*}{ Female } & 0.650 & -0.010 & 0.003 & 0.357 \\
\hline & $(0.602)$ & $(0.091)$ & $(0.133)$ & $(0.302)$ \\
\hline No. of obs. & 36600 & 36600 & 36600 & 36600 \\
\hline \multirow[t]{2}{*}{ Male } & $0.712^{* *}$ & 0.136 & 0.024 & 0.468 \\
\hline & $(0.347)$ & $(0.115)$ & $(0.106)$ & $(0.288)$ \\
\hline No. of obs. & 31565 & 31565 & 31565 & 31565 \\
\hline \multirow[t]{2}{*}{ White } & 1.336 & 0.163 & -0.083 & $0.939^{* *}$ \\
\hline & $(0.902)$ & $(0.141)$ & $(0.152)$ & $(0.369)$ \\
\hline No. of obs. & 45742 & 45742 & 45742 & 45742 \\
\hline \multirow[t]{2}{*}{ Black } & 0.076 & -0.124 & 0.042 & $-0.378^{* *}$ \\
\hline & $(0.270)$ & $(0.114)$ & $(0.093)$ & $(0.186)$ \\
\hline No. of obs. & 14051 & 14051 & 14051 & 14051 \\
\hline \multirow[t]{2}{*}{ Employed } & $0.645^{* * *}$ & 0.076 & -0.022 & $0.404^{* *}$ \\
\hline & $(0.240)$ & $(0.070)$ & $(0.095)$ & $(0.180)$ \\
\hline No. of obs. & 51360 & 51360 & 51360 & 51360 \\
\hline \multirow[t]{2}{*}{ Unemployed } & 0.554 & 0.010 & 0.152 & 0.215 \\
\hline & $(0.417)$ & $(0.142)$ & $(0.099)$ & $(0.191)$ \\
\hline No. of obs. & 16362 & 16362 & 16362 & 16362 \\
\hline \multirow[t]{2}{*}{ Married } & -90.542 & -16.387 & -8.066 & -32.507 \\
\hline & $(1756.075)$ & $(320.487)$ & $(156.337)$ & $(631.549)$ \\
\hline No. of obs. & 20210 & 20210 & 20210 & 20210 \\
\hline \multirow[t]{2}{*}{ Poor/near poor } & $1.440^{* *}$ & 0.196 & 0.229 & $0.581^{*}$ \\
\hline & $(0.718)$ & $(0.398)$ & $(0.222)$ & $(0.316)$ \\
\hline No. of obs. & 19837 & 19837 & 19837 & 19837 \\
\hline \multirow[t]{2}{*}{ Low income } & 0.223 & 0.091 & 0.064 & $0.303^{*}$ \\
\hline & $(0.247)$ & $(0.118)$ & $(0.090)$ & $(0.157)$ \\
\hline No. of obs. & 12924 & 12924 & 12924 & 12924 \\
\hline \multirow[t]{2}{*}{ Middle/high income } & 0.801 & -0.005 & -0.098 & 0.437 \\
\hline & $(0.610)$ & $(0.116)$ & $(0.133)$ & $(0.336)$ \\
\hline No. of obs. & 35404 & 35404 & 35404 & 35404 \\
\hline
\end{tabular}

Notes: Estimates from IV models with an age bandwidth of two years are reported. All models contain a quadratic polynomial of the forcing variable that is also fully interacted with the treatment variable. All models contain a set of control variables as discussed in the text. In all regressions, sample weights are used and standard errors are clustered by the forcing variable. Standard errors are reported in parentheses. The signs **, $* *$, and $* * *$ denote statistical significance at 10, 5, and 1 percent. 
Table 14. The effect of health insurance coverage on the number of visits for different types of health care use: IV estimates

\begin{tabular}{|c|c|c|c|c|}
\hline & Office & $\begin{array}{l}\text { Emergency } \\
\text { department }\end{array}$ & Outpatient & Dentist \\
\hline \multirow[t]{2}{*}{ Full sample } & 0.605 & 0.051 & 0.010 & $0.663^{* * *}$ \\
\hline & $(0.727)$ & $(0.080)$ & $(0.137)$ & $(0.182)$ \\
\hline No. of obs. & 68165 & 68165 & 68165 & 68165 \\
\hline \multirow[t]{2}{*}{ Female } & -0.644 & -0.026 & 0.038 & $0.650^{*}$ \\
\hline & $(0.927)$ & $(0.128)$ & $(0.222)$ & $(0.349)$ \\
\hline No. of obs. & 36600 & 36600 & 36600 & 36600 \\
\hline \multirow{2}{*}{ Male } & 1.675 & 0.113 & -0.015 & $0.638^{*}$ \\
\hline & $(1.043)$ & $(0.125)$ & $(0.149)$ & $(0.334)$ \\
\hline No. of obs. & 31565 & 31565 & 31565 & 31565 \\
\hline \multirow[t]{2}{*}{ White } & 1.091 & 0.179 & -0.081 & $1.250 * *$ \\
\hline & $(1.509)$ & $(0.184)$ & $(0.259)$ & $(0.489)$ \\
\hline No. of obs. & 45742 & 45742 & 45742 & 45742 \\
\hline \multirow[t]{2}{*}{ Black } & -0.386 & $-0.282^{*}$ & 0.087 & -0.331 \\
\hline & $(0.389)$ & $(0.149)$ & $(0.139)$ & $(0.220)$ \\
\hline No. of obs. & 14051 & 14051 & 14051 & 14051 \\
\hline \multirow[t]{2}{*}{ Employed } & 0.653 & 0.078 & -0.158 & $0.660^{* * *}$ \\
\hline & $(0.708)$ & $(0.088)$ & $(0.122)$ & $(0.199)$ \\
\hline No. of obs. & 51360 & 51360 & 51360 & 51360 \\
\hline \multirow[t]{2}{*}{ Unemployed } & 0.000 & -0.063 & 0.582 & 0.219 \\
\hline & $(1.429)$ & $(0.181)$ & $(0.369)$ & $(0.288)$ \\
\hline No. of obs. & 16362 & 16362 & 16362 & 16362 \\
\hline \multirow[t]{2}{*}{ Married } & -181.199 & -16.025 & -10.162 & -40.971 \\
\hline & (3498.695) & $(313.264)$ & (196.735) & $(795.576)$ \\
\hline No. of obs. & 20210 & 20210 & 20210 & 20210 \\
\hline \multirow[t]{2}{*}{ Poor/near poor } & 2.545 & 0.162 & 0.349 & $0.993^{*}$ \\
\hline & $(1.813)$ & $(0.447)$ & $(0.317)$ & $(0.537)$ \\
\hline No. of obs. & 19837 & 19837 & 19837 & 19837 \\
\hline \multirow[t]{2}{*}{ Low income } & 0.812 & 0.086 & 0.073 & $0.340^{*}$ \\
\hline & $(0.659)$ & $(0.126)$ & $(0.151)$ & $(0.181)$ \\
\hline No. of obs. & 12924 & 12924 & 12924 & 12924 \\
\hline \multirow[t]{2}{*}{ Middle/high income } & -0.209 & -0.024 & -0.162 & $0.725^{*}$ \\
\hline & $(1.317)$ & $(0.117)$ & $(0.224)$ & $(0.406)$ \\
\hline No. of obs. & 35404 & 35404 & 35404 & 35404 \\
\hline
\end{tabular}

Notes: Estimates from IV models with an age bandwidth of two years are reported. All models contain a quadratic polynomial of the forcing variable that is also fully interacted with the treatment variable. All models contain a set of control variables as discussed in the text. In all regressions, sample weights are used and standard errors are clustered by the forcing variable. Standard errors are reported in parentheses. The signs *, **, and *** denote statistical significance at 10,5 , and 1 percent. 
Figure 1. The change in insurance coverage status at the $26^{\text {th }}$ birthday

A. Any insurance

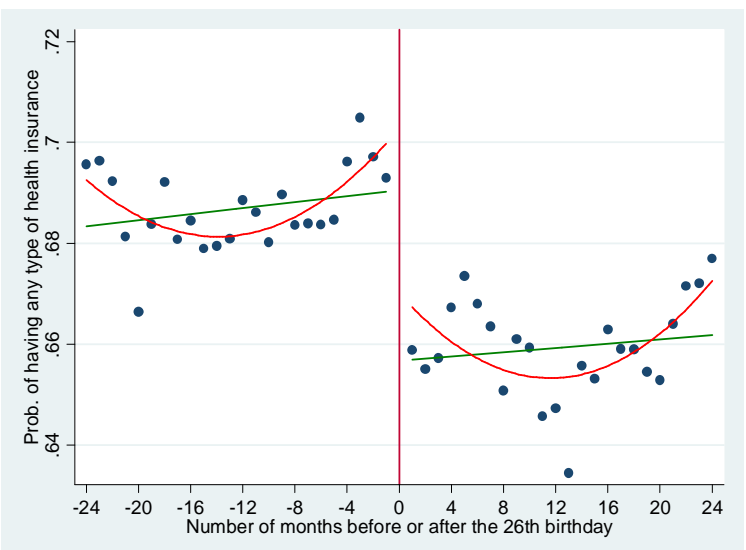

C. Public insurance

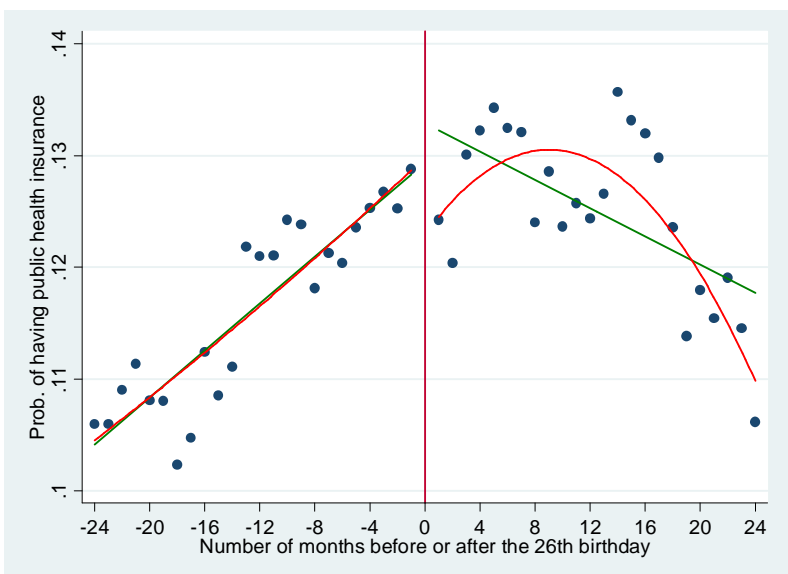

B. Private insurance

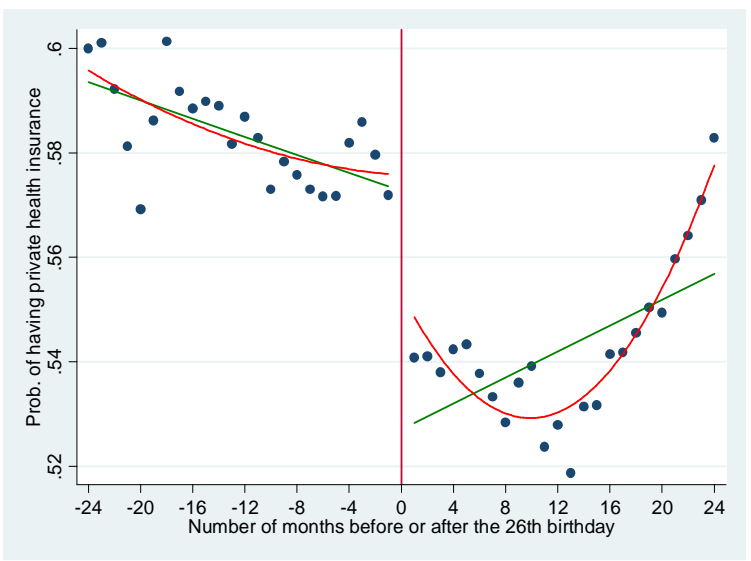

D. Ins. holder outside of RU

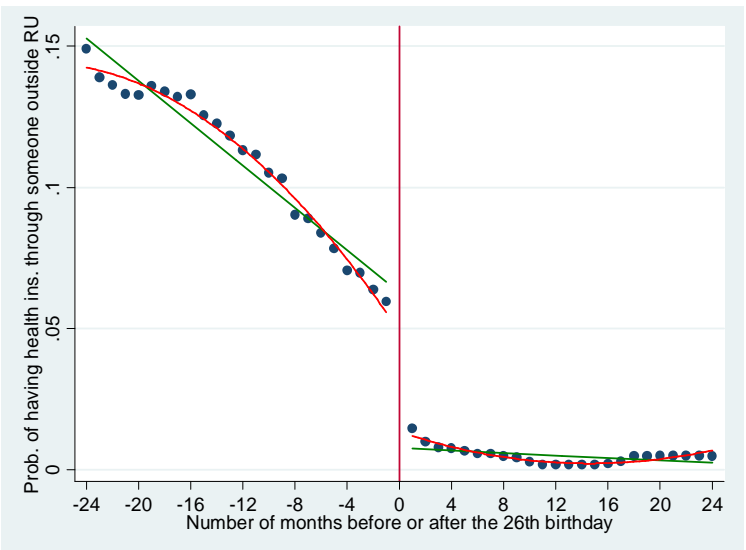

Notes: Mean of the outcome variables for 1 month intervals two years before and after the $26^{\text {th }}$ birthday are plotted. The solid lines are the first and second order polynomials fitted on individual observations on both sides of the age- 26 cutoff as reported in the first two specifications of Table 3 . 
Figure 2. The change in office visits and related costs at the $26^{\text {th }}$ birthday

A. Prob. of visit

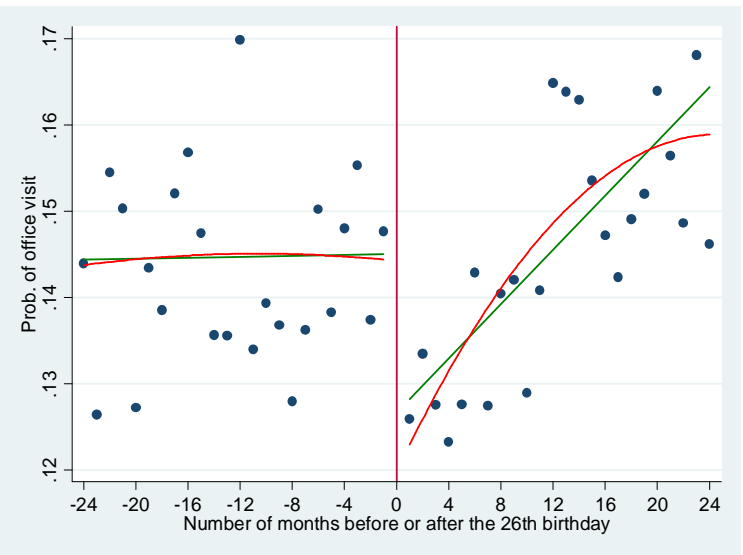

C. Total payment

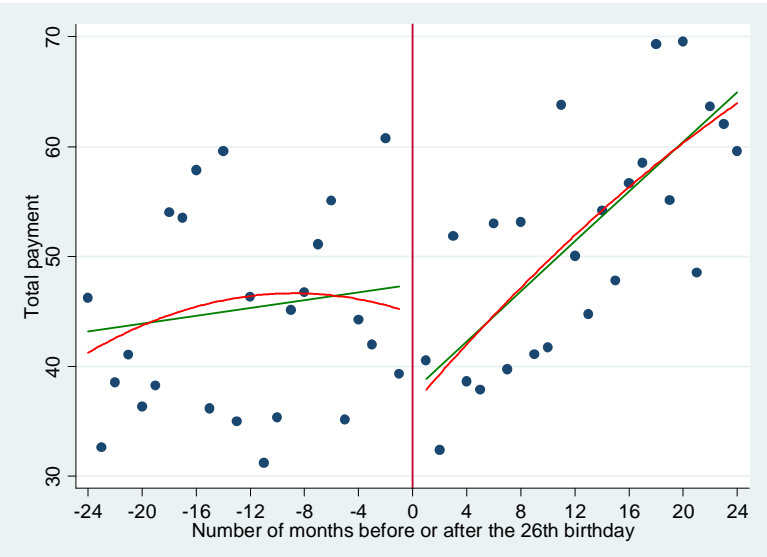

B. No. of visits

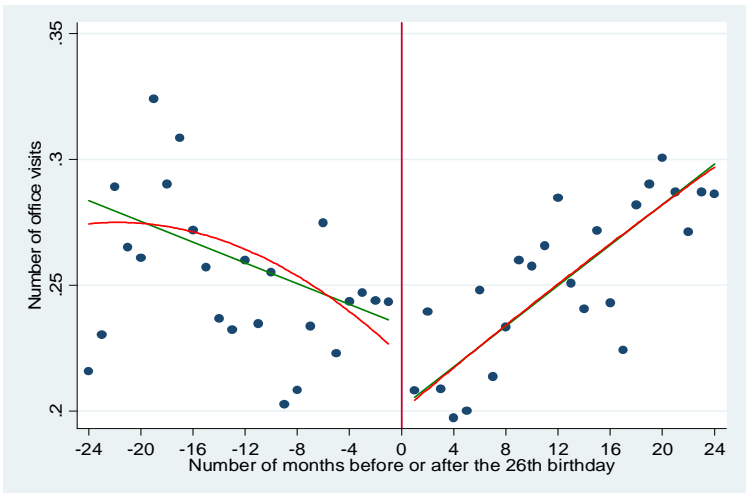

D. Out of pocket cost

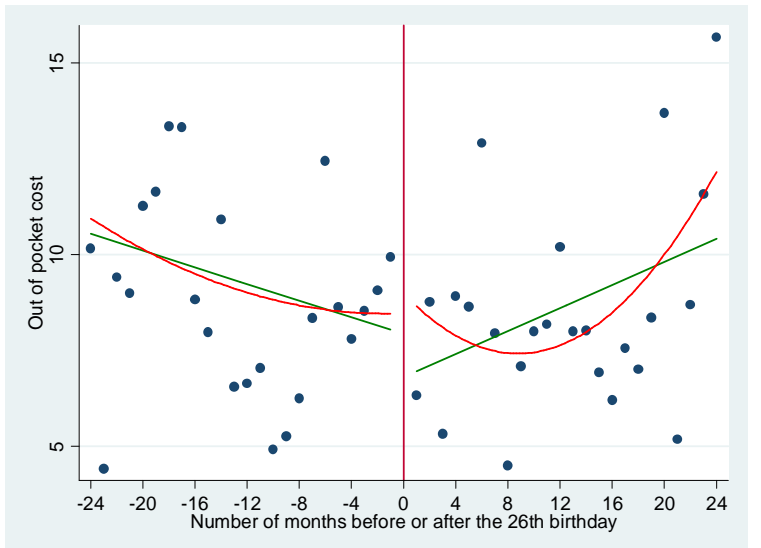

Notes: Mean of the outcome variables for 1 month intervals two years before and after the $26^{\text {th }}$ birthday are plotted. The solid lines are the first and second order polynomials fitted on individual observations on both sides of the age- 26 cutoff as reported in the first two specifications of Table 4. 
Figure 3 . The change in outpatient visits and related costs at the $26^{\text {th }}$ birthday

A. Prob. of visit

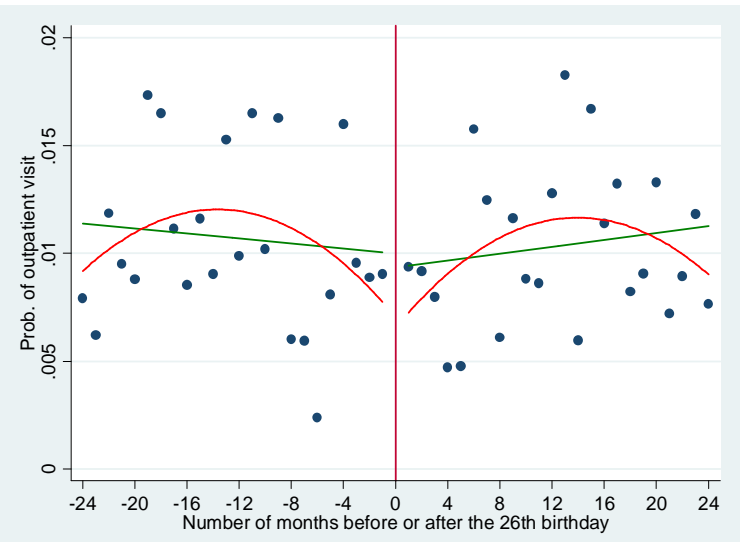

C. Total payment

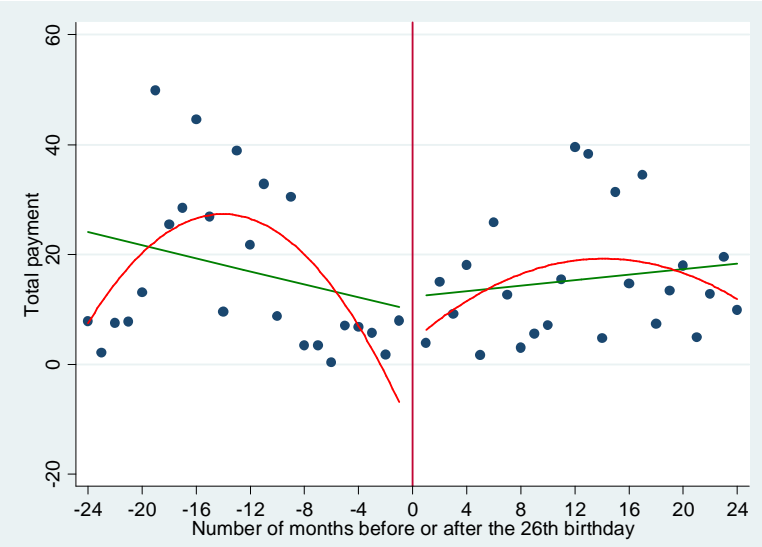

B. No. of visits

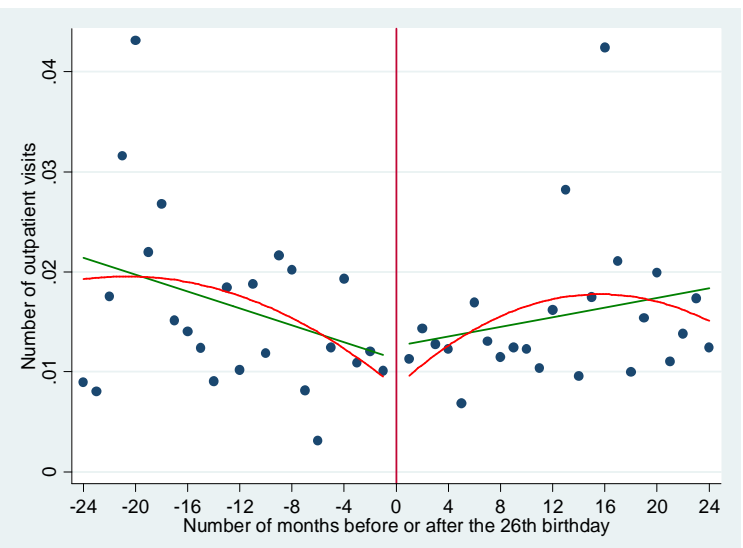

D. Out of pocket cost

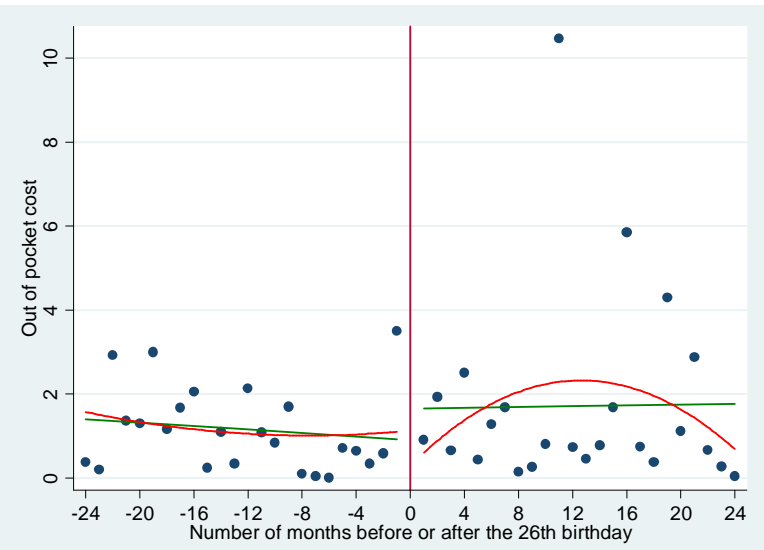

Notes: Mean of the outcome variables for 1 month intervals two years before and after the $26^{\text {th }}$ birthday are plotted. The solid lines are the first and second order polynomials fitted on individual observations on both sides of the age- 26 cutoff as reported in the first two specifications of Table 5 
Figure 4 . The change in dental visits and related costs at the $26^{\text {th }}$ birthday

A. Prob. of visit

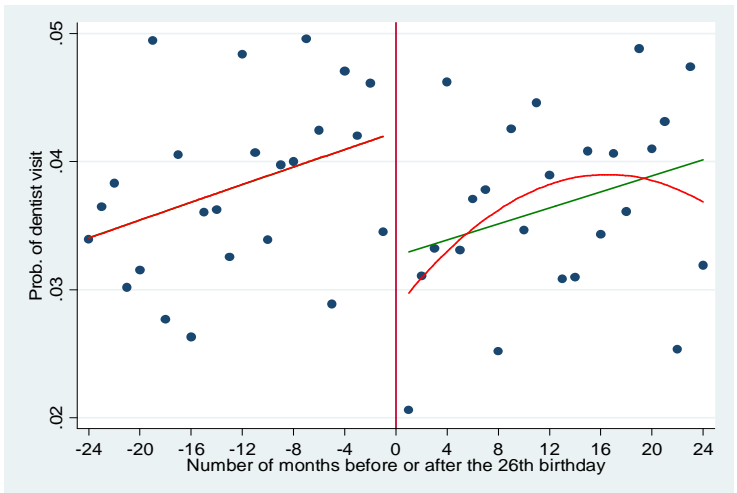

C. Total payment

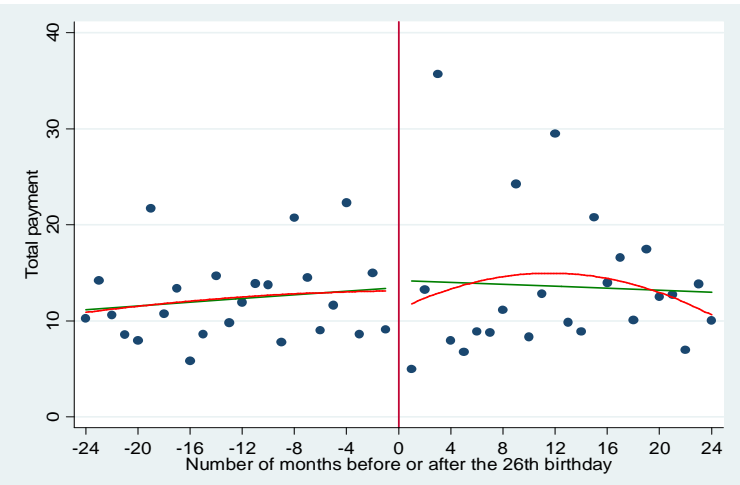

B. No. of visits

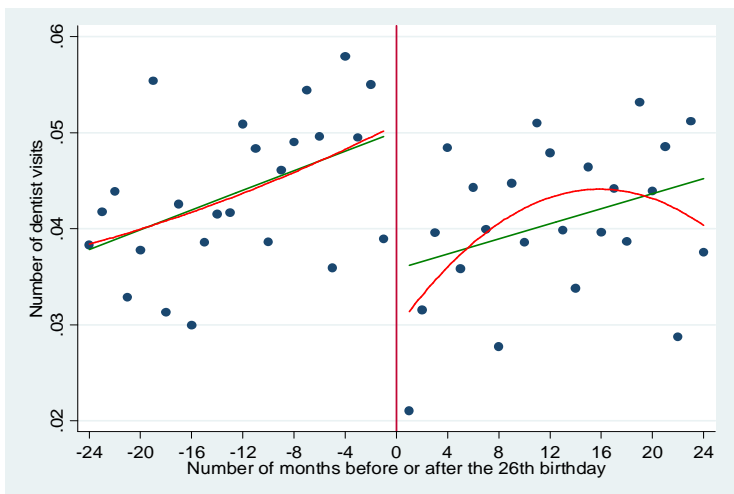

D. Out of pocket cost

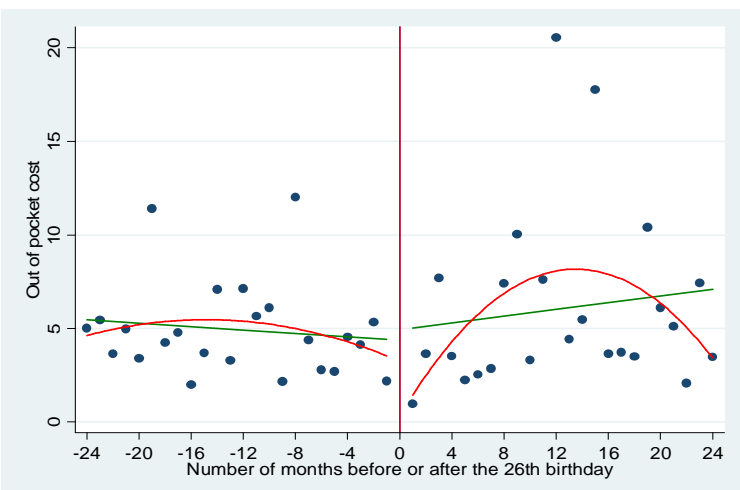

Notes: Mean of the outcome variables for 1 month intervals two years before and after the $26^{\text {th }}$ birthday are plotted. The solid lines are the first and second order polynomials fitted on individual observations on both sides of the age-26 cutoff as reported in the first two specifications of Table 6 . 
Figure 5. The change in emergency room visits and related costs at the $26^{\text {th }}$ birthday

A. Prob. of visit

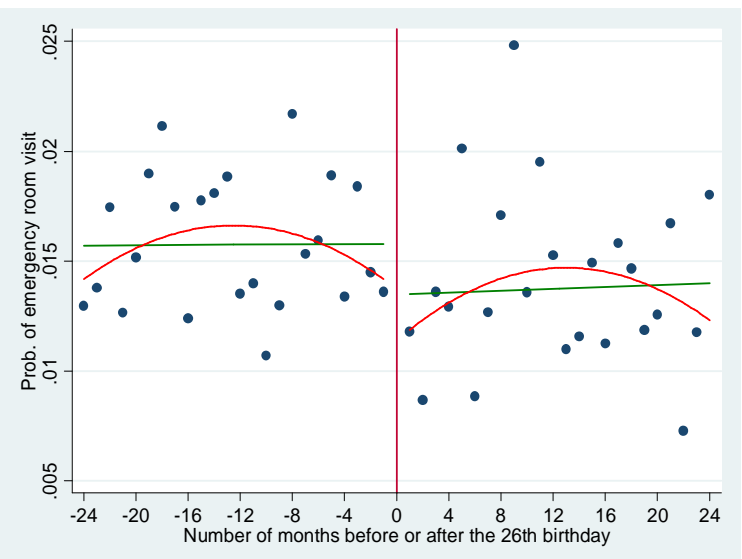

C. Total payment

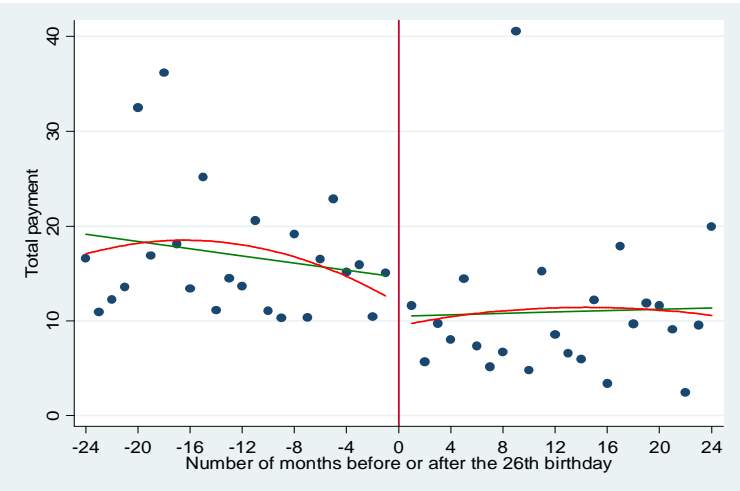

B. No. of visits

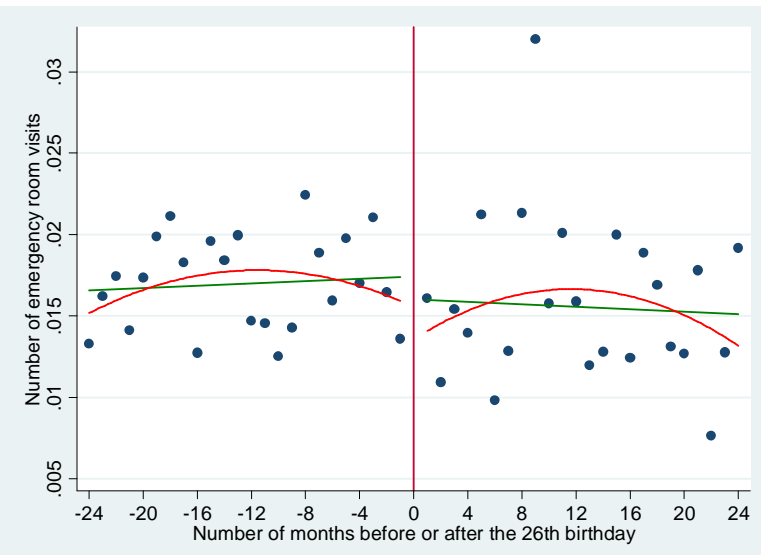

D. Out of pocket cost

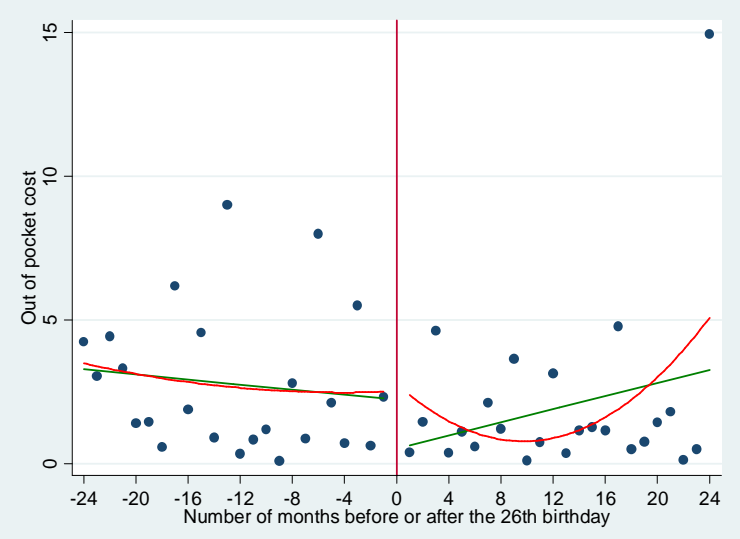

Notes: Mean of the outcome variables for 1 month intervals two years before and after the $26^{\text {th }}$ birthday are plotted. The solid lines are the first and second order polynomials fitted on individual observations on both sides of the age- 26 cutoff as reported in the first two specifications of Table 7 . 


\section{Appendix}

Figure A1. Distribution of the number of observations by month

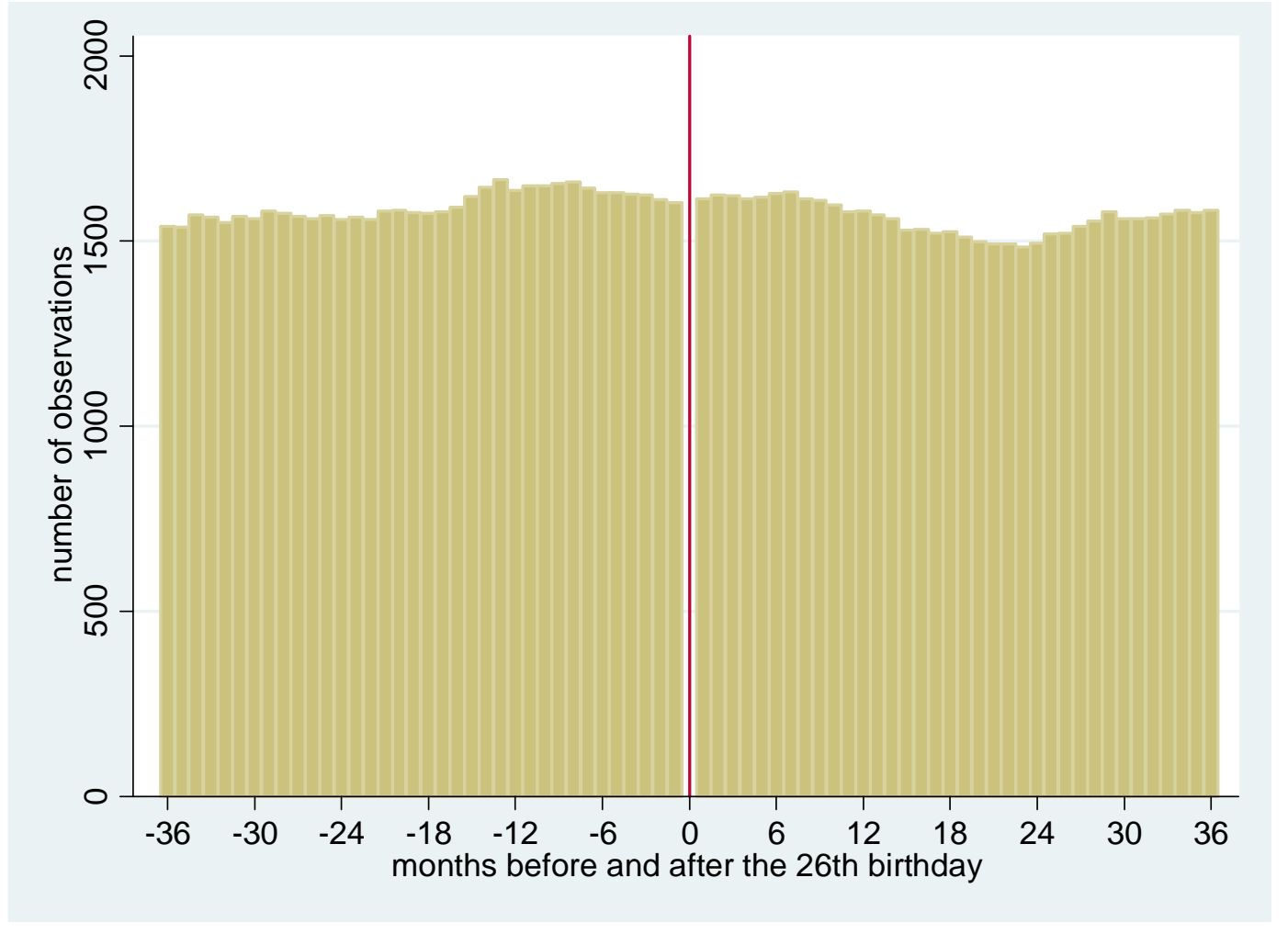

Notes: Number of observations for each month three years before and after the $26^{\text {th }}$ birthday is plotted. 
Figure A2. The change in selected control variables at the $26^{\text {th }}$ birthday

A. Excellent health

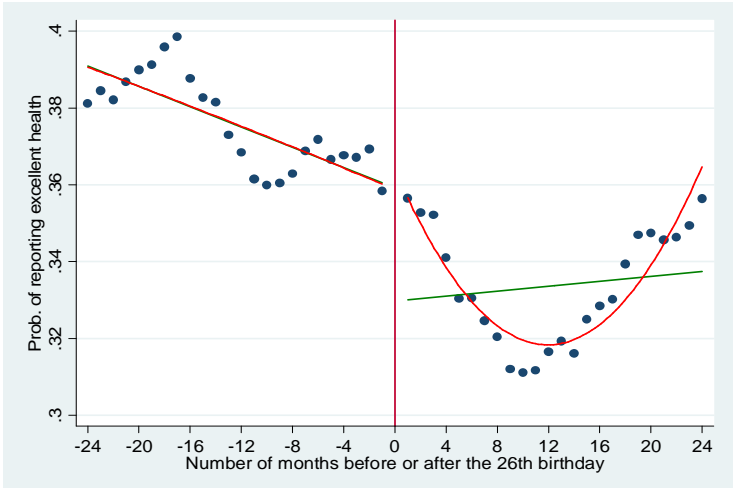

C. Family size

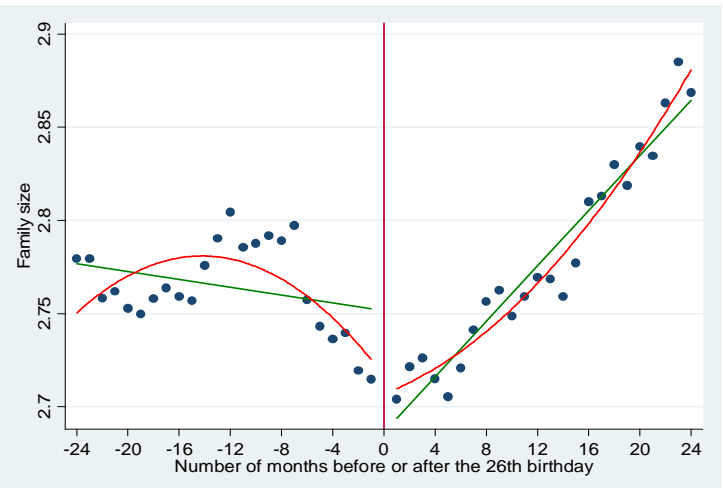

E. Married

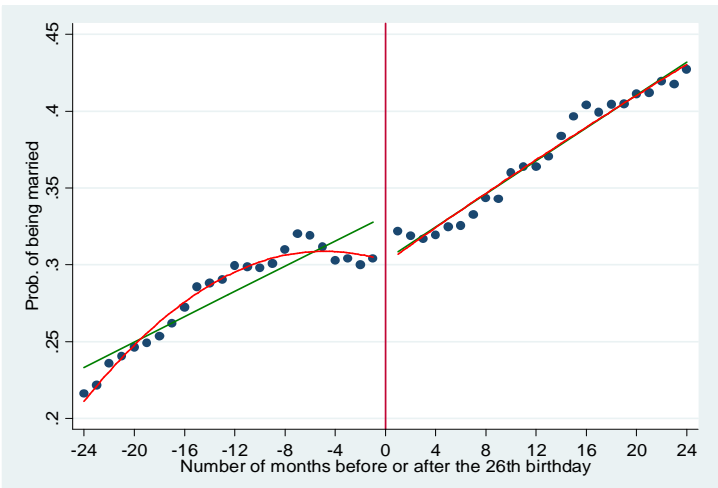

B. Ln(Family income)

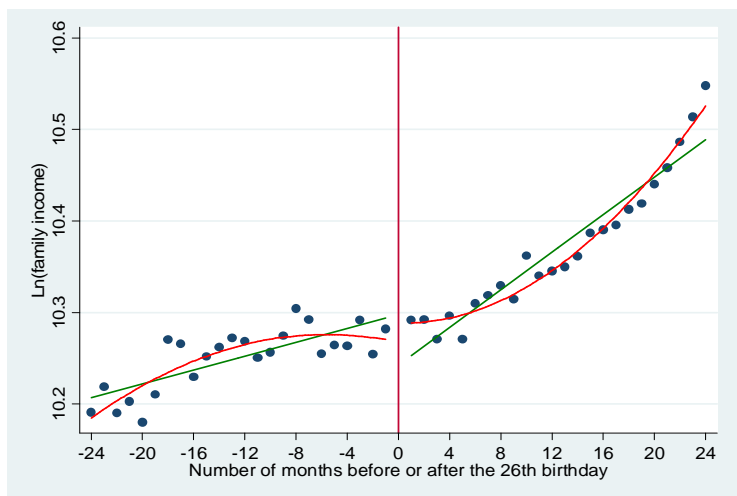

D. Advanced degree

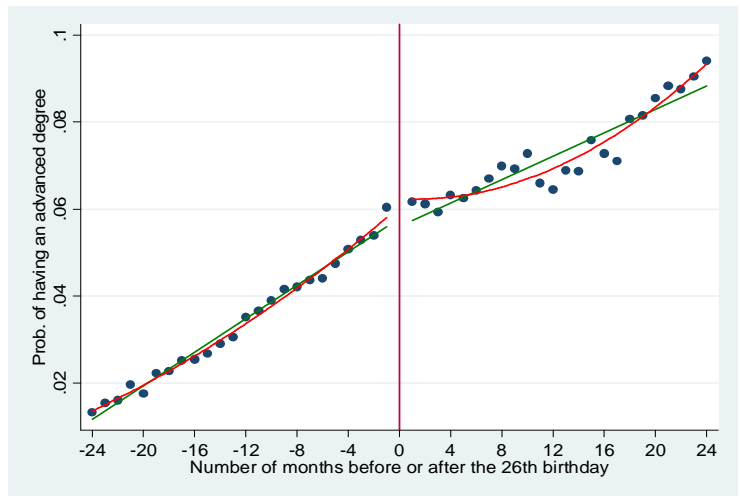

F. Female

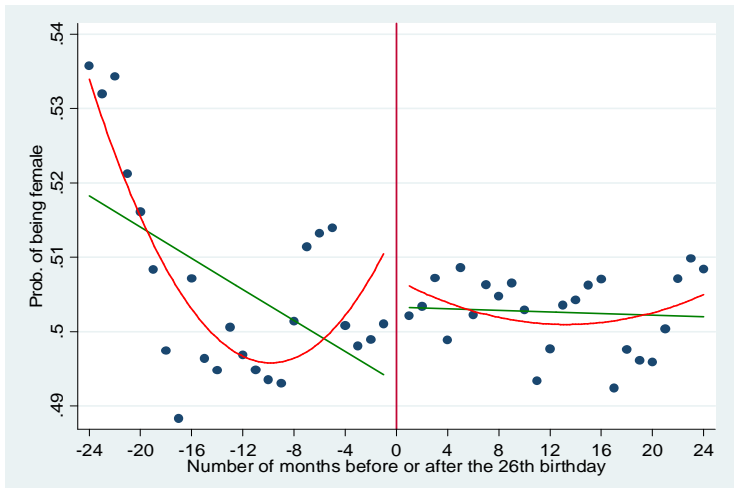

Notes: Mean of the selected control variables for 1 month intervals two years before and after the $26^{\text {th }}$ birthday are plotted. The solid lines are the first and second order polynomials fitted on individual observations on both sides of the age- 26 cutoff. 
Figure A3. Probability of using health care up to six months before the $25^{\text {th }}, 26^{\text {th }}$, and $27^{\text {th }}$ birthdays

A. Office

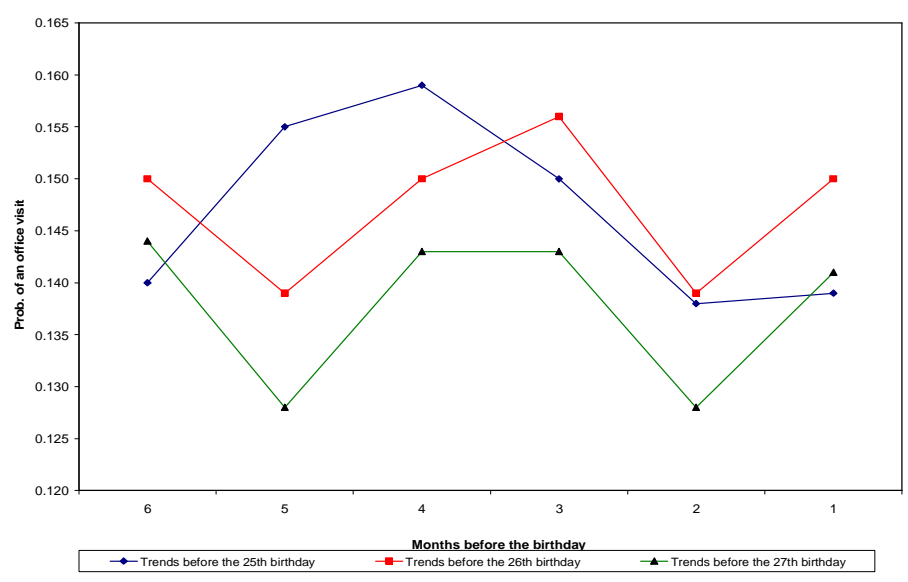

C. Outpatient

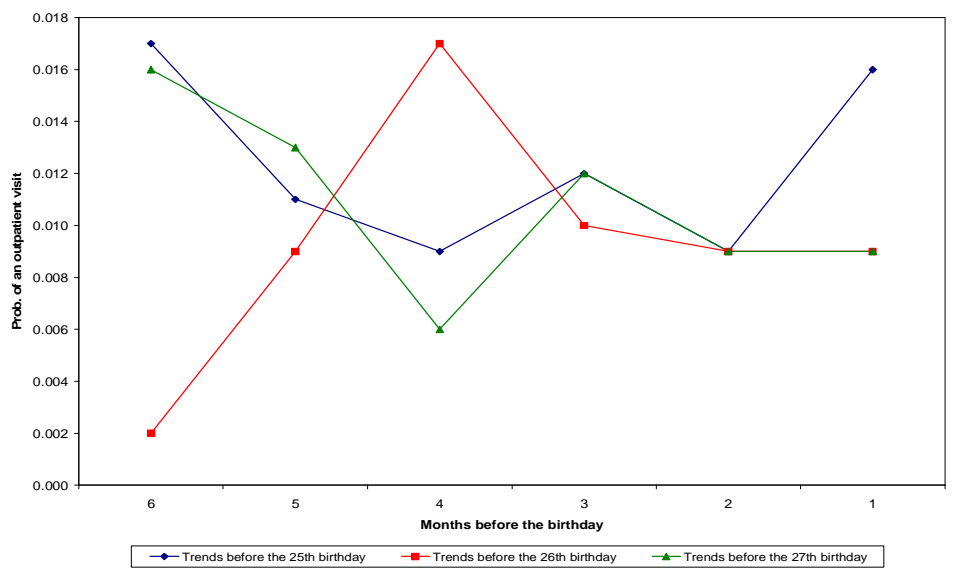

B. Emergency department

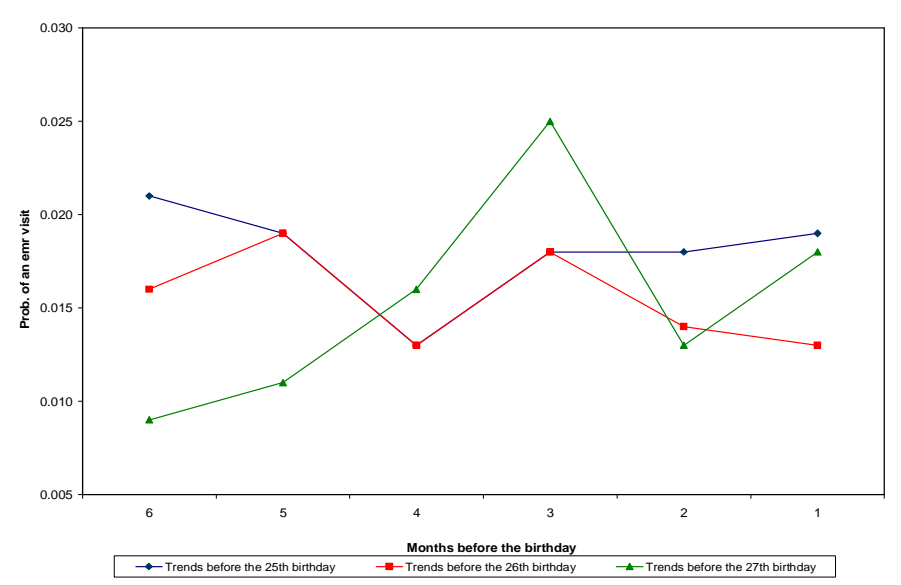

D. Dentist

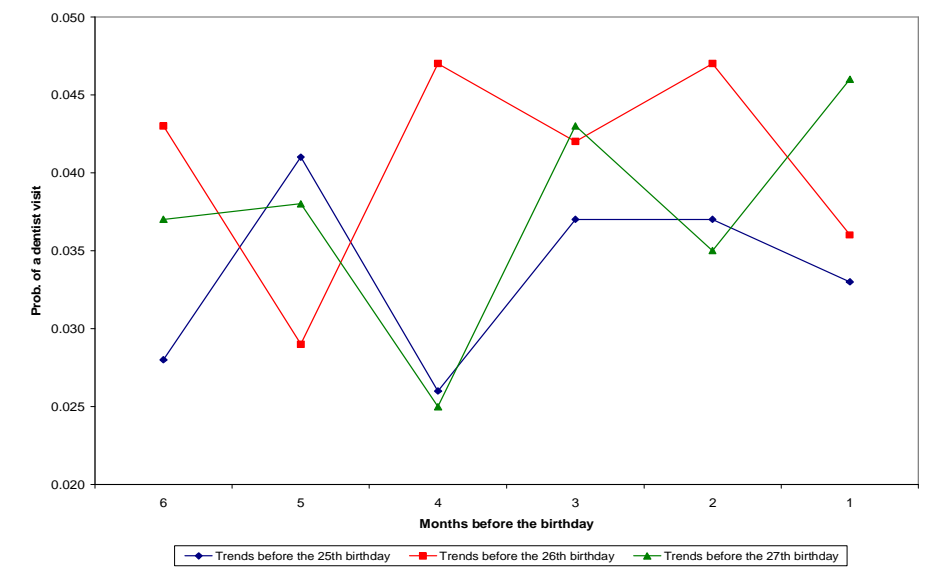

